Article

\title{
Improvement of Energy Efficiency and Control Performance of Cooling System Fan Applied to Industry 4.0 Data Center
}

\author{
Jae-Sub Ko ${ }^{1}$, Jun-Ho Huh ${ }^{2}$ and Jong-Chan Kim ${ }^{3, * \mathbb{D}}$ \\ 1 Department of Electric Control Engineering, Sunchon National University, 255 Jungang-ro, \\ Suncheon-city Jeollanam do 57922, Korea; kokos22@sunchon.ac.kr \\ 2 Department of Software, Catholic University of Pusan, Geumjeong-gu, 57 Oryundae-ro, \\ Busan 46252, Korea; 72networks@pukyong.ac.kr \\ 3 Department of Computer Engineering, Sunchon National University, 255 Jungang-ro, \\ Suncheon-city Jeollanam do 57922, Korea \\ * Correspondence: seaghost@sunchon.ac.kr; Tel.: +82-61-750-3620
}

Received: 19 April 2019; Accepted: 23 May 2019; Published: 25 May 2019

check for updates

\begin{abstract}
This paper proposes a control method to improve the energy efficiency and performance of cooling fans used for cooling. In Industry 4.0, a large number of digital data are used, and a large number of data centers are created to handle these data. These data centers consist of information technology (IT) equipment, power systems, and cooling systems. The cooling system is essential to prevent failure and malfunction of the IT equipment, which consumes a considerable amount of energy. This paper proposes a method to reduce the energy used in such cooling systems and to improve the temperature control performance. This paper proposes an fuzzy proportional integral(FPI) controller that controls the input value of the proportional integral(PI) controller by the fuzzy controller according to the operation state, a VFPI (Variable Fuzzy Proportional Integral) controller that adjusts the gain value of the fuzzy controller, and a variable fuzzy proportion integration-variable limit (VFPI-VL) controller that adjusts the limit value of the fuzzy controller's output value. These controllers control the fan applied to the cooling system and compare the energy consumed and temperature control performance. When the PI controller consumes $100 \%$ of the power consumed, the FPI is $50.5 \%$, the VFPI controller is $44.3 \%$, and the VFPI-VL is $32.6 \%$. The power consumption is greatly reduced. In addition, the VFPI-VL controller is the lowest in temperature variation, which improves the energy efficiency and performance of the cooling system using a fan. The methods presented in this paper can not only be applied to fans for cooling, but also to variable speed systems for various purposes and improvement of performance and efficiency can be expected.
\end{abstract}

Keywords: Cooling system; fan; Fuzzy controller; PI controller; Industry 4.0; Data Center; Embedded Systems; computer architecture

\section{Introduction}

The central characteristic of Industry 4.0 is the convergence of information and communication technologies. Industry 4.0 combines new technological innovation in six fields: Big Data Analysis, Artificial Intelligence, Robotics, Internet of Things, Unmanned Transportation, 3D Printing, and Nanotechnology [1]. This industry 4.0 utilizes a large number of digital data, including personal information. In addition, a large number of data are created from personal information, from who we are, where we have been, and where we plan to go, to bank details and heart rate [2]. As a result, the number of large-scale data centers is increasing rapidly around the world, and interest in energy consumption of data centers is increasing [3]. These data centers account for more than $1 \%$ of global 
electricity usage. They consist of IT facilities, power systems, cooling and ventilation systems. Among these components, IT equipment consumes from 30\% to $50 \%$ of total energy, and cooling and ventilation systems consume $\sim 40 \%$ of total energy [4]. In order to reduce energy consumption, it is necessary to control the flow of the bottom air efficiently. In order to reduce power consumed in the data center, Google has used AI control, resulting in a reduction in energy consumption of $\sim 40 \%$ [5].

Temperature management of electronic devices constituting these data centers is very important, and problems arising during the operation of electrical equipment are mostly caused by temperature [6]. Methods for managing the temperature include air cooling, liquid cooling, heat pipes, refrigeration cooling, thermoelectric cooling, and phase change material-based cooling methods. Of these, air cooling and liquid cooling are the simplest and most commonly used methods. Cooling methods applied to the data center include air-based cooling and liquid-based cooling. The air-based cooling method cools the IT equipment with cooled air passing into the equipment, and the efficiency and performance change depending on the method of construction. Water is widely used to cool all types of mechanical and industrial systems, but the risks associated with leakage are too high to be used directly to cool data center servers, and special equipment and solutions are needed [6,7].

The air-based cooling method can improve cooling efficiency by forcibly circulating heated air, and the liquid-based cooling method can also improve the cooling efficiency by forcibly lowering the temperature of the heated liquid. In general, a fan is used to circulate air and lower the temperature of the heated liquid. Depending on the performance of the fan, the cooling performance can be influenced.

A thermoelectric device is a device that converts electrical energy into thermal energy and thermal energy into electrical energy. In particular, due to its ability to generate electrical energy using heat, thermoelectric devices are environmentally friendly devices and have advantages in minimizing global warming and environmental pollution. In addition, the thermoelectric element can convert electric energy into heat energy and can be used as a heat source for cooling and heating. This feature allows it to be used in various applications ranging from producing electricity from the waste heat of automobiles to small applications like computers [8-10].

Cooling systems using thermoelectric elements include refrigerators using thermoelectric elements [11-18], electronic equipment coolers [19-27], dehumidifiers [28,29], and air conditioners [30]. In air conditioners in particular the performance of a hybrid system which combines the thermoelectric elements is $10 \%$ higher than conventional systems. As such, thermoelectric devices are used in a variety of temperature management applications.

Cooling using these thermoelectric elements can be presented as a unique solution to the problem of keeping the temperature lower than the indoor temperature and has many advantages as follows.

- It does not need any maintenance because there is no driving part.

- It is smaller and lighter than existing cooling systems and can be applied to various applications in various standard sizes.

- Both heating and cooling can be selected according to the polarity of the supplied DC power supply.

- Closed loop temperature control allows accurate temperature control over $+/-0.1^{\circ} \mathrm{C}$.

- The thermoelectric device has high reliability due to the solid state structure, and the lifetime of the thermoelectric device in general is over 200,000 hours.

- Since there is no driving part, it is noiseless and can be used with sensitive sensors.

- Thermoelectric devices are powered by DC power, so modules with wide input voltage and current can be used. Pulse width modulation (PWM) can be applied to various applications.

- It can be cooled to a lower temperature than the indoor temperature.

- Using the temperature difference of the thermoelectric elements, DC power can be produced.

- Conventional refrigeration systems use chlorofluorocarbons or other chemicals that can be harmful to the environment, but thermoelectric devices do not use or produce any kind of gas.

A thermoelectric element is a device in which heat absorption and generation occur simultaneously when DC power is input. When the thermoelectric element is cooled using the heat absorbing side 
of the thermoelectric element, heat is generated on the opposite side. Such a thermoelectric element generally has a structure for attaching a heat sink, and the cooling performance of the heat sink is greatly influenced by the thermal resistance of the selected heat sink. Therefore, it is very important to select a heat sink suitable for a cooling system when using a thermoelectric device for cooling [31,32]. The performance of the thermoelectric element can be expressed by COP (coefficient of performance), with COP representing the ratio of the amount of heat absorbed to the power input to the thermoelectric element. This ratio increases as the temperature difference between the heat absorbing side and the heat generating side of the thermoelectric element decreases, and the COP becomes very low when the temperature difference becomes larger. Therefore, efficient cooling of the heat generating side is essential for high COP [33].

Fuzzy control has been used to describe uncertain systems since it was first discovered by Professor Zadeh. Fuzzy control is used for the control of many industrial systems and has the advantage that it can be applied without accurate modeling [34-38]. The PI controller is the most widely used controller in the industrial field and has the advantage that the structure is simple, and thus the relationship between the gain and the control value is clear. However, the PI control has a limitation in satisfying both the transient state and the steady state due to the fixed gain value. In particular, there is a problem wherein a cumulative error occurs due to the integral operation. In order to solve this problem, a control scheme that automatically adjusts the gain of the PI controller has been researched. However, since the proportional gain and the integral gain are continuously calculated according to the operation state, the calculation amount increases and a high-performance CPU is necessary for fast processing. Therefore, in this paper, we propose a new control scheme consisting of a fuzzy controller and PI controller to solve these problems.

In this paper, we propose an FPI controller that controls the input value of the PI controller using fuzzy control, a VFPI controller that adjusts the fuzzy control gain of the FPI controller, and a variable fuzzy proportion integration-variable limit (VFPI-VL) controller that adjusts the output limit of the VFPI controller. The limitation of the performance improvement by the fixed gain value of the conventional PI controller can be solved by adjusting the input value using the fuzzy control and the control performance can be improved by adjusting the gain value of the fuzzy control and the limit value of the controller output. The control method proposed in this paper is applied to the control system using fan. The cooling system using the fan changes the power consumption according to the operating time and speed of the fan. The method proposed in this paper optimally controls the operation time and speed of the fan according to the operating conditions, thereby reducing the power consumption of the fan. The controller proposed in this paper can be applied to various variable speed drive systems, and it is expected to improve speed control performance and reduce power consumption.

This paper is organized as follows. In Section 2, the characteristics of thermoelectric devices are introduced. Section 3 shows the cooling system using a thermoelectric device. In Section 4, a new control method combining a fuzzy controller and PI controller is proposed. Section 5 shows the experimental results of the method proposed in this paper and the validity of said results are analyzed. Finally, Section 6 presents the conclusion and future work suggested by this paper.

\section{Characteristics of Thermoelectric Device}

The thermoelectric element is a semiconductor element that utilizes the Peltier effect. The Peltier effect is a phenomenon in which the heat absorption and heat generation appear according to the direction of the direct current as shown in Figure 1. It can be changed from cooling to heating by changing the direction of the current without mechanical change. 


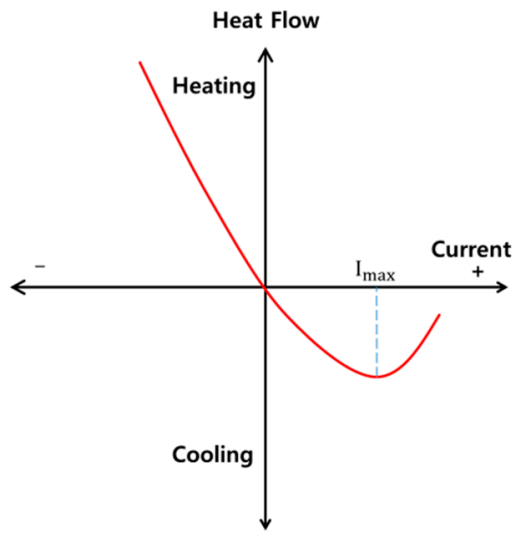

Figure 1. Principle of the dehumidifier.

These thermoelectric elements can maintain a temperature difference of up to $\sim 70{ }^{\circ} \mathrm{C}$. Such a thermoelectric device has the advantage that the affected area can be cooled to a temperature much lower than the ambient temperature, and it is possible to maintain the state of $\pm 0.01{ }^{\circ} \mathrm{C}$ even in a normal state [32]. Figure 2 shows the structure of the thermoelectric element [29].

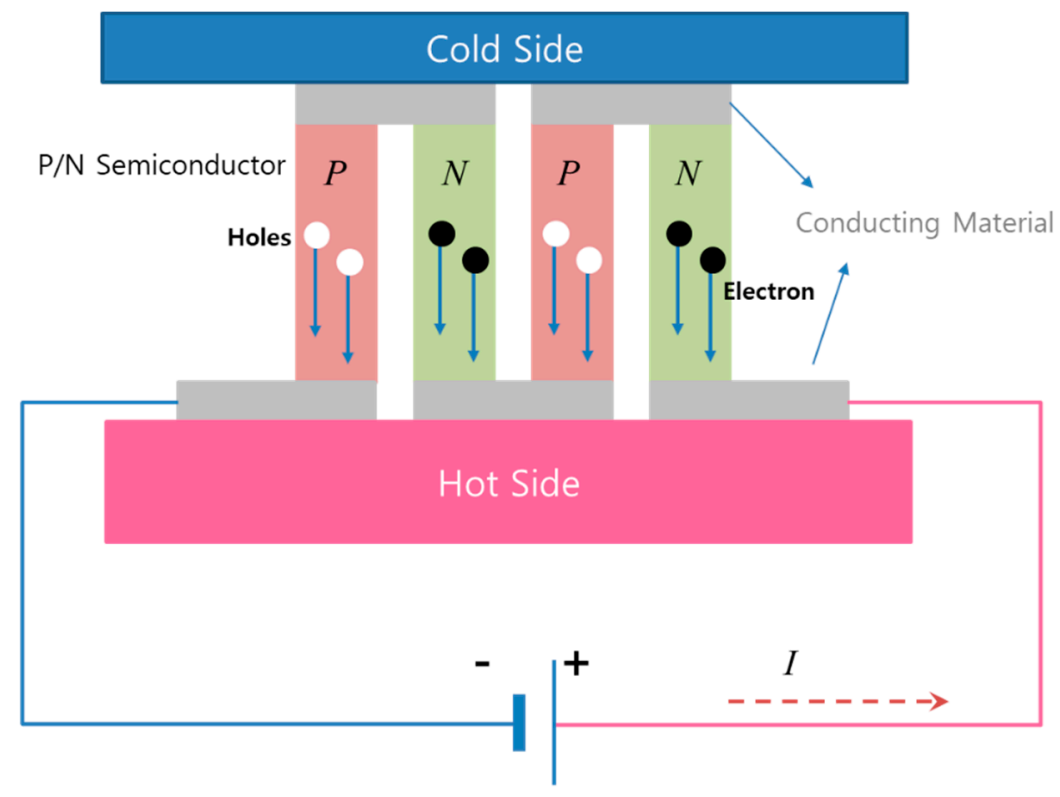

Figure 2. Principle of thermoelectric element.

The most important parameter in a cooling system using a thermoelectric element is the coefficient of performance (COP: $\varphi$ ). The COP $(\varphi)$ can be calculated as shown in Equation (1).

$$
\varphi=\frac{\mathrm{Q}_{\mathrm{c}}}{\mathrm{P}}
$$

where $Q_{C}$ is the amount of heat absorbed on the cold side and $\mathrm{P}$ is the input power. The heat absorbed amount $\left(Q_{c}\right)$ is the sum of heat due to the Peltier effect, Joule heat, and heat conduction. The $Q_{c}$ can be calculated as shown in Equation (2).

$$
Q_{c}=\alpha \cdot T_{c} \cdot I-\frac{1}{2} \cdot I^{2} \cdot R-K \cdot \Delta T
$$

where, $\alpha=\alpha_{p}+\alpha_{n}, \alpha_{p}, \alpha_{n}$ is the Seebeck coefficient of $\mathrm{P}$ and $\mathrm{N}$ type semiconductor $(\mathrm{V} / \mathrm{K}), \mathrm{I}$ is the current $(A), R$ is the electric resistance $(\Omega)$, and $K$ is coefficient of thermal coefficient $(\mathrm{W} / \mathrm{m} \Delta \mathrm{K})$, 
respectively. $\Delta \mathrm{T}\left(\Delta \mathrm{T}=\mathrm{T}_{\mathrm{h}}-\mathrm{T}_{\mathrm{c}}\right)$ is the temperature difference between the cold side and the hot side of thermoelectric device $\left({ }^{\circ} \mathrm{C}\right), \mathrm{T}_{\mathrm{h}}$ is the hot side temperature $\left({ }^{\circ} \mathrm{C}\right)$, and $\mathrm{T}_{\mathrm{C}}$ is the cold side temperature $\left({ }^{\circ} \mathrm{C}\right)$.

The current can be expressed as Equation (3) using the voltage generated by the Seebeck effect and the supply voltage. The input power $P$ is the sum of the power and the joule heat generated by the Seebeck effect and can be expressed as Equation (4) [39,40].

$$
\begin{gathered}
I=\frac{V-\alpha \cdot \Delta T}{R} \\
P=V \cdot I=\alpha \cdot \Delta T \cdot I+I^{2} \cdot R=V \cdot \frac{(V-\alpha \cdot \Delta T)}{R}
\end{gathered}
$$

\section{Cooling System using Thermoelectric Device}

When a thermoelectric device is used for cooling in Figure 1, when a current higher than the maximum current $\left(I_{\max }\right)$ is supplied, the temperature rises again due to the internal power loss $\left(I^{2} R\right)$. Therefore, care should be taken not to exceed the maximum current when using thermoelectric elements. Cooling using a thermoelectric element can cause the temperature to drop lower than the surrounding temperature, and has the advantage of precise temperature control. In addition, it can go from cooling to heating by changing the direction of the current without mechanical changes. In cooling using the thermoelectric device, when the supplied current to the thermoelectric device is more than maximum current $\left(\mathrm{I}_{\max }\right)$, there is a problem wherein the power loss consumed in the thermoelectric element increases and the temperature rises again. Therefore, care should be taken so that the supplied current does not exceed the maximum current $\left(\mathrm{I}_{\max }\right)$.

Figure 3 shows a cooling system using a thermoelectric element. The object temperature $\left(T_{0}\right)$ represents the temperature required for cooling and is the temperature of the heat absorbing side (Cold Side) of the thermoelectric element. The heat sink temperature $\left(\mathrm{T}_{\mathrm{HS}}\right)$ represents the temperature of the heat sink attached to the heat generation side (Hot Side) of the thermoelectric element. $\Delta \mathrm{T}$ is the difference in temperature between $T_{0}$ and $T_{H S}$. $T_{a m b}$ represents the ambient air temperature. The maximum value of $\Delta \mathrm{T}$ has a limit value for every thermoelectric device. When the temperature of the ambient air is constantly maintained, $\mathrm{T}_{\mathrm{HS}}$ must be lowered in order to lower $\mathrm{T}_{\mathrm{o}}$.

$$
\begin{gathered}
\mathrm{T}_{\mathrm{HS}}=\mathrm{T}_{\mathrm{amb}}+\Delta \mathrm{T}_{\mathrm{HS}} \\
\mathrm{T}_{\mathrm{o}}=\mathrm{T}_{\mathrm{HS}}-\Delta \mathrm{T}=\mathrm{T}_{\mathrm{amb}}+\Delta \mathrm{T}_{\mathrm{HS}}-\Delta \mathrm{T}
\end{gathered}
$$

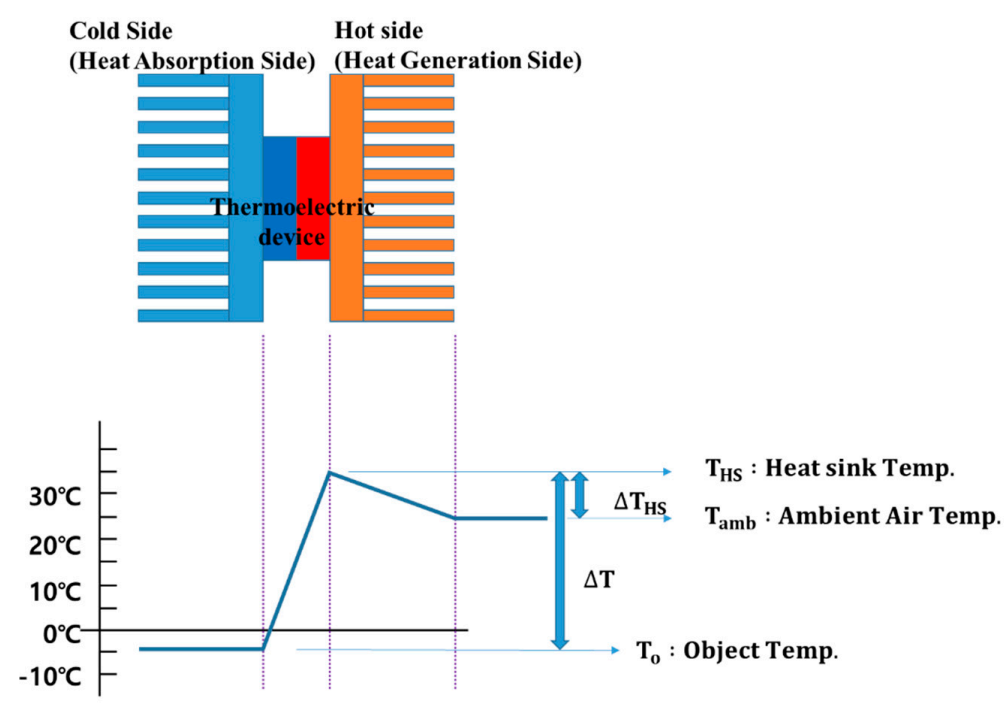

Figure 3. Thermoelectric cooling system temperature characteristics. 
Figure 4 shows the characteristics of the thermoelectric element 9501/127/040 B model [41]. The maximum current $\left(\mathrm{I}_{\max }\right)$ of this model is $4 \mathrm{~A}$, the maximum voltage $\left(\mathrm{V}_{\max }\right)$ is $17.5 \mathrm{~V}$, the maximum temperature difference $\Delta \mathrm{T}$ is $72{ }^{\circ} \mathrm{C}$, and the maximum heat absorbing amount $\left(Q_{c_{\max }}\right)$ is $38 \mathrm{~W}$. Figure $4 \mathrm{a}$ shows the comparison of the heat absorption amount $\left(\mathrm{Q}_{c}\right)$ according to the current and the temperature difference and Figure $4 \mathrm{~b}$ shows the comparison of the COP (coefficient of performance) according to the current and the temperature difference. As shown in Figure 4, when the temperature difference $(\Delta \mathrm{T})$ increases, the heat absorption and COP decrease. Therefore, in order to improve the cooling performance of the cooling system using the thermoelectric element, the temperature difference between the high temperature surface and the low temperature surface of the thermoelectric element must be reduced. For this purpose, high temperature surface cooling performance is very important.

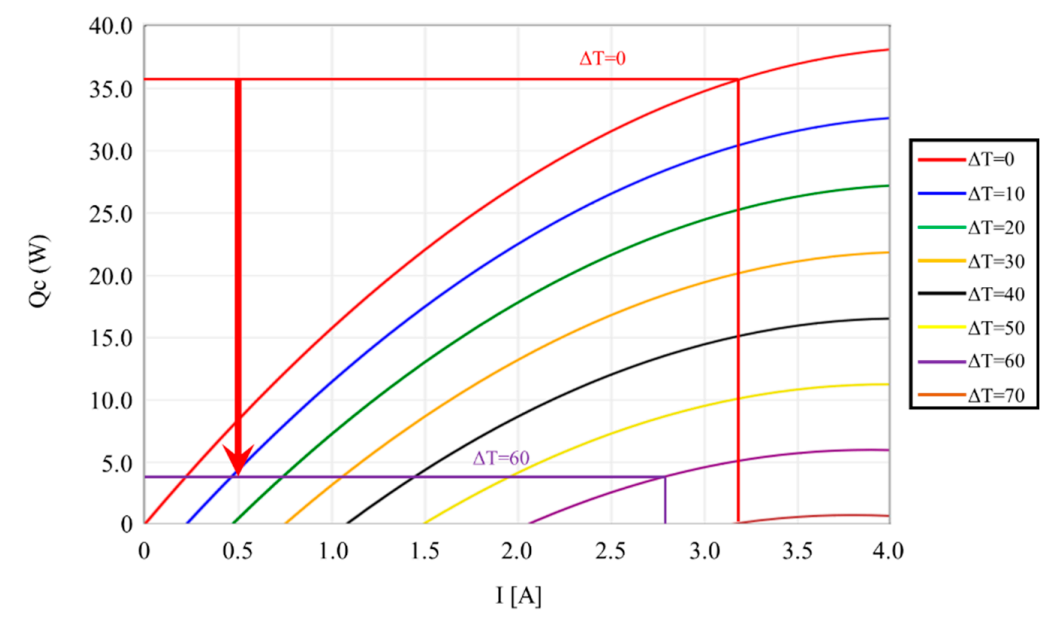

(a)

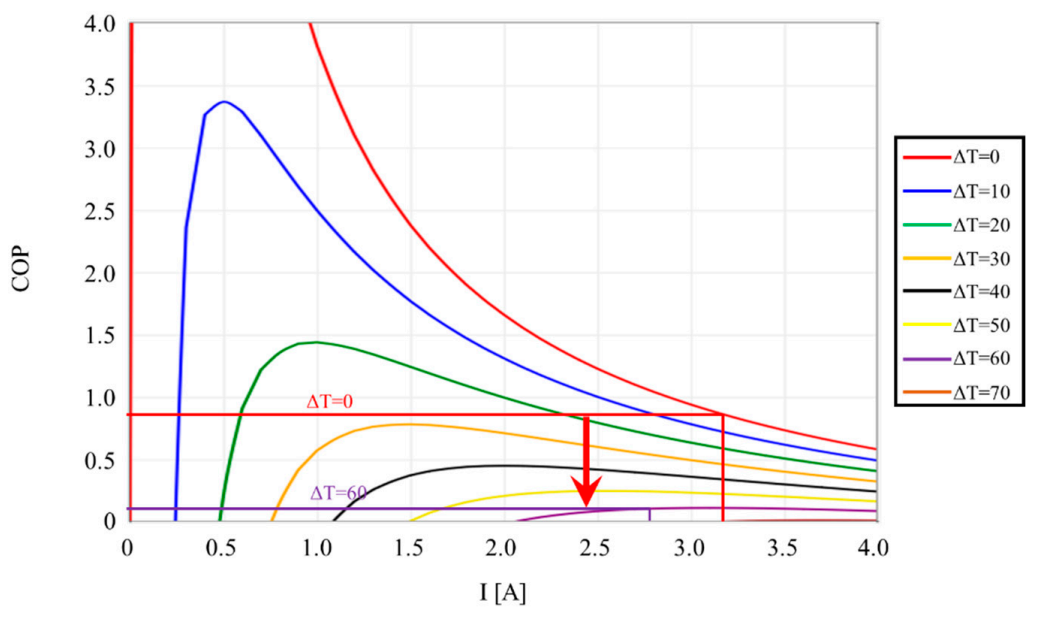

(b)

Figure 4. Temperature characteristic of thermoelectric device. (a)heat absorption amount $\left(\mathrm{Q}_{\mathrm{c}}\right)$; (b) Coefficient of performance (COP).

\section{Proposed Control Method}

The PI controller is the most widely used controller in the industrial field. The PI controller performs control using two gain values (proportional gain and integral gain), and the rise time, overshoot, stabilization time, and qualitative state error are changed according to these gain values. There are various methods to set the gain of the PI controller, but we use a lot of trial and error methods that do not require mathematical knowledge and can be controlled in real time. The integral operation of the PI control causes the problem of saturating the control value due to an error occurring in the steady state, thereby causing the problem of delaying the control in the next transient state. This 
problem is called the wind-up phenomenon, and the way to prevent it is called anti-wind-up. In this paper, we use the method depicted in Figure 5 for anti-wind-up. In Figure $5, \mathrm{u}_{\mathrm{c}}(\mathrm{k})$ is before the limit, and $u(k)$ is the PI controller output after the limit. The error value $\left(e_{u}(k)\right)$ between these two values is calculated by Equation (7). If this value $\left(\mathrm{e}_{\mathrm{u}}(\mathrm{k})\right)$ is generated, it can be determined that the saturation of the output value of the PI controller has occurred. Since the saturation phenomenon of the output value of the PI controller is generated by the integral control, the input value of the integral control is reduced by the Equation (8) using the output value error $\left(\mathrm{e}_{\mathrm{u}}(\mathrm{k})\right)$, as the result the integral output is adjusted. The control amount of PI controller is given by Equation (11) and the change of control amount $(\Delta \mathrm{u})$ can be expressed as Equation (13) by using the current output $\mathrm{u}(\mathrm{k})$ and previous output $\mathrm{u}(\mathrm{k}-1)$.

$$
\begin{aligned}
& \mathrm{e}_{\mathrm{u}}(\mathrm{k})=\mathrm{u}_{\mathrm{c}}(k)-u(k) \\
& \mathrm{e}_{\mathrm{i}}(k)=e_{\mathcal{c}}(k)-K_{s} \cdot e_{u}(k) \\
& u(k)=\mathrm{e}_{\mathrm{c}}(k) \cdot K_{p}+K_{i} \int e_{i}(\tau) d \tau \\
& \int_{0}^{t_{k}} e_{i}(\tau) \mathrm{d} \tau=\sum_{i=1}^{k} e_{i}\left(t_{i}\right) \mathrm{t}_{\mathrm{s}} \\
& u(k)=\mathrm{e}_{\mathrm{c}}(k) \cdot K_{p}+K_{i} \sum_{i=1}^{k} e_{i}\left(t_{i}\right) \mathrm{t}_{\mathrm{s}} \\
& u(k)-u(k-1)=\left\{\mathrm{e}_{\mathrm{c}}(k) \cdot K_{p}+K_{i} \sum_{i=1}^{k} e\left(t_{i}\right) \mathrm{t}_{\mathrm{s}}\right\}-\left\{\mathrm{e}_{\mathrm{c}}(k-1) \cdot K_{p}+K_{i} \sum_{i=1}^{k-1} e\left(t_{i}\right) \mathrm{t}_{\mathrm{s}}\right\} \\
& =K_{p}\left\{e_{c}(k)-e_{c}(k-1)\right\}+K_{i} e_{c}(k) t_{s} \\
& \Delta u=u(k)-u(k-1)
\end{aligned}
$$

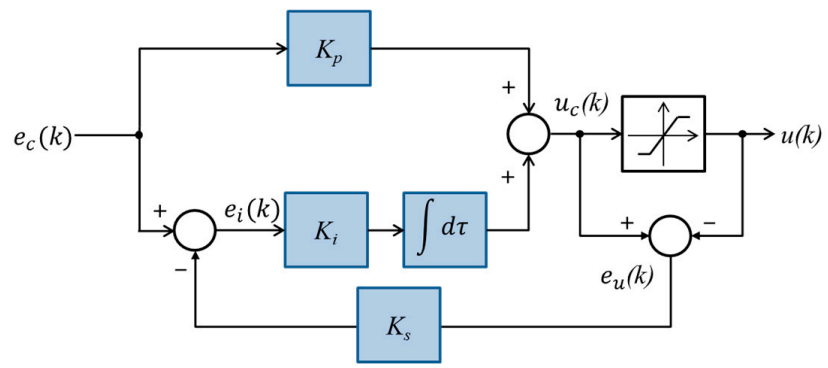

Figure 5. PI controller with anti-wind-up.

In order to solve the disadvantages of PI controller with fixed gain, methods of adjusting gain value have been proposed [42-44]. The PI controller uses the proportional gain and the integral gain. In order to automatically adjust the gain value, the PI controller has to calculate the two values according to the operation state, which increases the calculation time. To solve this problem, a high-performance CPU is required. Therefore, in this paper, we propose a method to adjust the input value of PI controller to solve the problem of fixed gain of PI controller. When the input value is adjusted, only one controller is used. Therefore, the calculation time is faster than the method of adjusting the gain value.

In this paper, a fuzzy controller is used to improve the performance of the PI controller. Fuzzy control is a system that does not require mathematical modeling and is robust in dealing with transient conditions. The rule base in Table 1 represents 49 rules that are commonly used in fuzzy control. The rule base in Table 1 is used for temperature control, PWM control of inverter for wind power generation, and fuzzy control for controlling gain of proportional integral differential (PID) controller, as well as motor speed control [45-47]. If the level increases, the control variable is also increased by 
one level. This method can adjust the control amount in proportion to the change of the input value. The membership function of fuzzy control is shown Figure 6. Membership functions use triangles and trapezoids the most. We use the triangle membership function which has advantages in real time control. Figure 6 shows the membership function used in this paper. Fuzzy control is a control method that uses the ambiguity of the boundary; the fuzzy membership function shows the degree of membership of the input value. In this paper, membership range of membership function is used as follows. The required control amount according to the input value is set as Large, Medium, Small, and Zero according to the size, and it is divided into seven parts as positive and negative according to the control direction. The parameter of the membership function is used as a percentage of input value. For fast control speed, the range of NL, NM, PM, PL is set large, ZE is smallest, and NS and PS are medium. For this, we have designed membership function as follows; the range of ZE is -0.2 to 0.2 , PS and NS are $|0 \sim 0.6|, \mathrm{NM}$ and PM are $|0.2 \sim 1|$, and NL and PL are |above 0.6|. In this paper, 49 rules were used. The number of rules affects computation time and system performance. If the number of rules is large, the calculation time increases but the control performance is the best [48-51]. Therefore, in this paper, we used 49 rules, which show the best control performance because the change in temperature is not fast. Figure 7 shows the general form of the fuzzy controller. The input to the fuzzy controller is the error and error value, and the gain values GE and GC are used to scale the input range -1 to 1 of the membership function of the graph. In addition, the output value through the defuzzification is multiplied by the gain value GU to scale it to a controllable variable $[29,52,53]$.

Table 1. Rule base of fuzzy controller.

\begin{tabular}{|c|c|c|c|c|c|c|c|}
\hline ce & NL & NM & NS & $\mathrm{ZE}$ & PS & PM & PL \\
\hline NL & NL & NL & NL & NL & NM & NS & $\mathrm{ZE}$ \\
\hline NM & NL & NL & NL & $\mathrm{NM}$ & NS & $\mathrm{ZE}$ & PS \\
\hline NS & NL & NL & $\mathrm{NM}$ & NS & $\mathrm{ZE}$ & PS & $\mathrm{PM}$ \\
\hline ZE & NL & NM & NS & ZE & PS & PM & PL \\
\hline PS & $\mathrm{NM}$ & NS & $\mathrm{ZE}$ & PS & PM & PL & PL \\
\hline $\mathrm{PM}$ & NS & ZE & PS & $\mathrm{PM}$ & PL & PL & PL \\
\hline PL & ZE & PS & PM & PL & PL & PL & PL \\
\hline
\end{tabular}

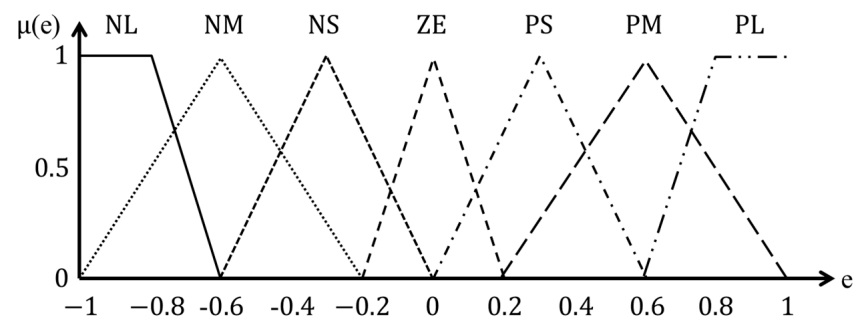

(a)

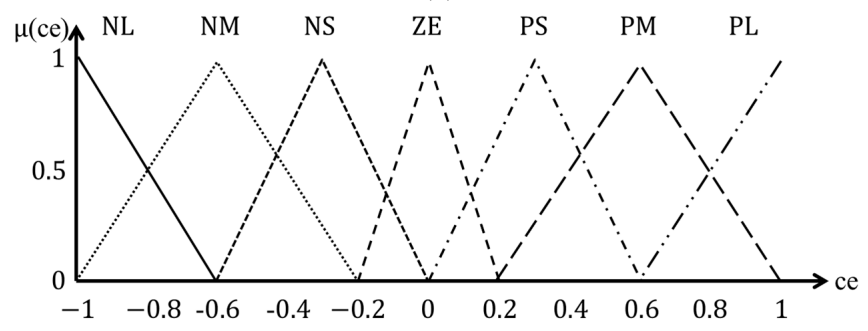

(b)

Figure 6. Cont. 


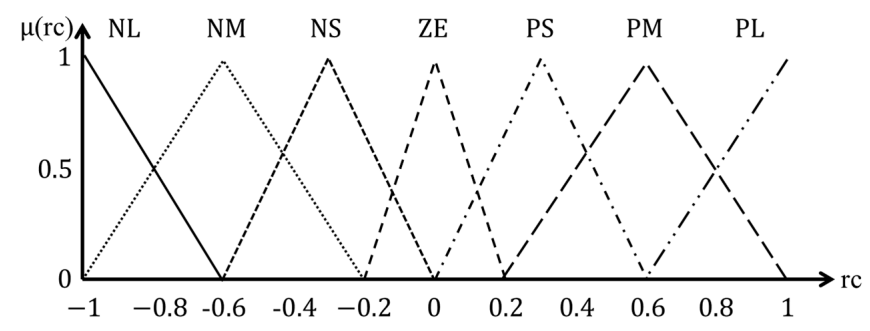

(c)

Figure 6. Membership function for the input value (error(e) and changing error(ce)): (a) The error (e) membership function, (b) the changing error (ce) membership function, and (c) output membership function.

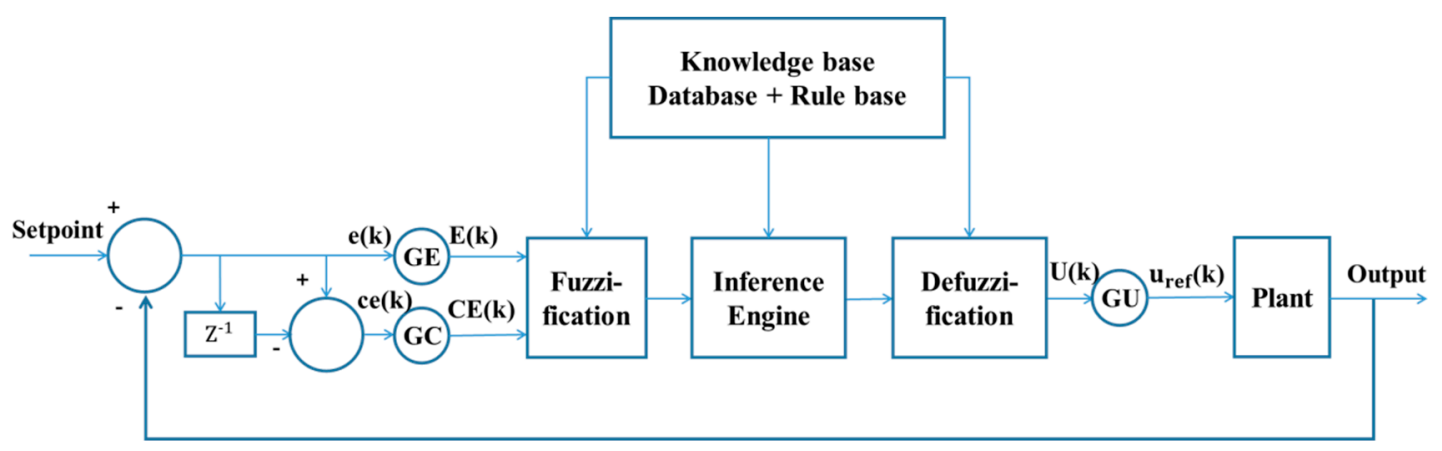

Figure 7. The general structure of the fuzzy controller.

$$
\begin{gathered}
\mathrm{E}(\mathrm{k})=\mathrm{e}(\mathrm{k}) \times \mathrm{GE} \\
\mathrm{CE}(\mathrm{k})=\mathrm{ce}(\mathrm{k}) \times \mathrm{GC} \\
\mathrm{u}(\mathrm{k})=\mathrm{U}(\mathrm{k}) \times \mathrm{GU}
\end{gathered}
$$

In this paper, the hot side of a thermoelectric device is cooled by a fan in a thermoelectric cooling system. Traditionally, the PI controller has difficulty selecting the suitable gain and is limited in performance improvement due to fixed gain. To improve its performance, this paper proposes a fuzzy proportional integration (FPI) controller that adjusts the input value of the PI controller by fuzzy control. Figure 8 shows a block diagram of the FPI controller.

$$
\begin{aligned}
& \Delta \mathrm{T}=\mathrm{T} \_ \text {Hot }(\mathrm{k})-\mathrm{T} \_ \text {Cold }(\mathrm{k}) \\
& \mathrm{e}(\mathrm{k})=\Delta \mathrm{T}(\mathrm{k})-\mathrm{SET} \_\mathrm{Tem} \\
& \mathrm{ce}(\mathrm{k})=\mathrm{e}(\mathrm{k})-\mathrm{e}(\mathrm{k}-1) \\
& \operatorname{Com\_ Tem}(k)=\frac{\sum_{\mathrm{i}=1}^{\mathrm{n}}(\mathrm{rc})_{\mathrm{i}} \cdot \mu\left[(\mathrm{rc})_{\mathrm{i}}\right]}{\sum_{\mathrm{i}=1}^{\mathrm{n}} \mu\left[(\mathrm{rc})_{\mathrm{i}}\right]} \\
& \text { Com_Ref }(\mathrm{k})=\text { Com_Tem }(\mathrm{k})+\Delta \mathrm{T} \\
& \mathrm{e}_{\mathrm{c}}(\mathrm{k})=\mathrm{Com}_{\operatorname{Ref}(\mathrm{k})}-\text { SET_Tem } \\
& \operatorname{PWM}(\mathrm{k})_{\text {ref }}=\operatorname{PWM}(\mathrm{k}-1)_{\text {ref }}+\Delta \mathrm{u} \\
& =\operatorname{PWM}(\mathrm{k}-1)_{\text {ref }}+\mathrm{K}_{\mathrm{p}}\left\{\mathrm{e}_{\mathrm{c}}(\mathrm{k})-\mathrm{e}_{\mathrm{c}}(\mathrm{k}-1)\right\}+\mathrm{K}_{\mathrm{i}} \Delta \mathrm{e}_{\mathrm{c}}(\mathrm{k}) \Delta \mathrm{t}_{\mathrm{s}}
\end{aligned}
$$




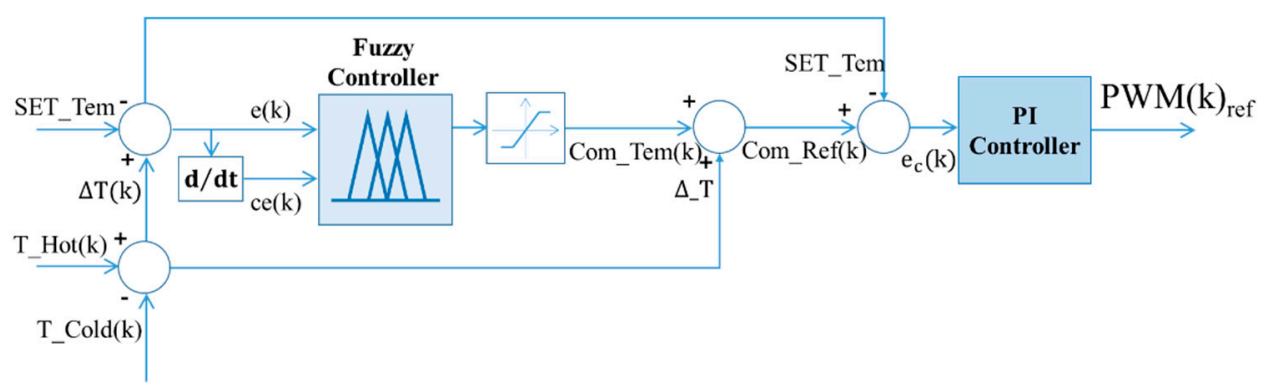

Figure 8. Structure of FPI controller.

$\Delta \mathrm{T}$ is the temperature difference between the hot side of the thermoelectric element (T_Hot) and the cold side (T_Cold), and SET_Tem is the set temperature difference. The fuzzy controller outputs the compensation temperature (Com_Tem), which compensates the temperature difference according to the operating state, with error and error change value inputs. $\Delta \mathrm{T}$ is added to the compensation temperature (Com_Tem) and compared with the set temperature (SET_Tem), and the PI controller outputs a PWM (Pulse Width Modulation) signal for speed control of the fan. In this paper, the input value of PI is controlled by fuzzy control. In Figure 7, the output (U) through the defuzzification is multiplied by the gain value (GU) to output the control value $\left(\mathrm{u}_{\mathrm{ref}}\right)$. This paper proposes a method to automatically adjust the output gain of fuzzy control according to the operating state. The output gain control of the fuzzy control uses a PI controller, and Figure 9 shows a VFPI (variable gain fuzzy proportional integration) controller that adjusts the output gain of the fuzzy controller.

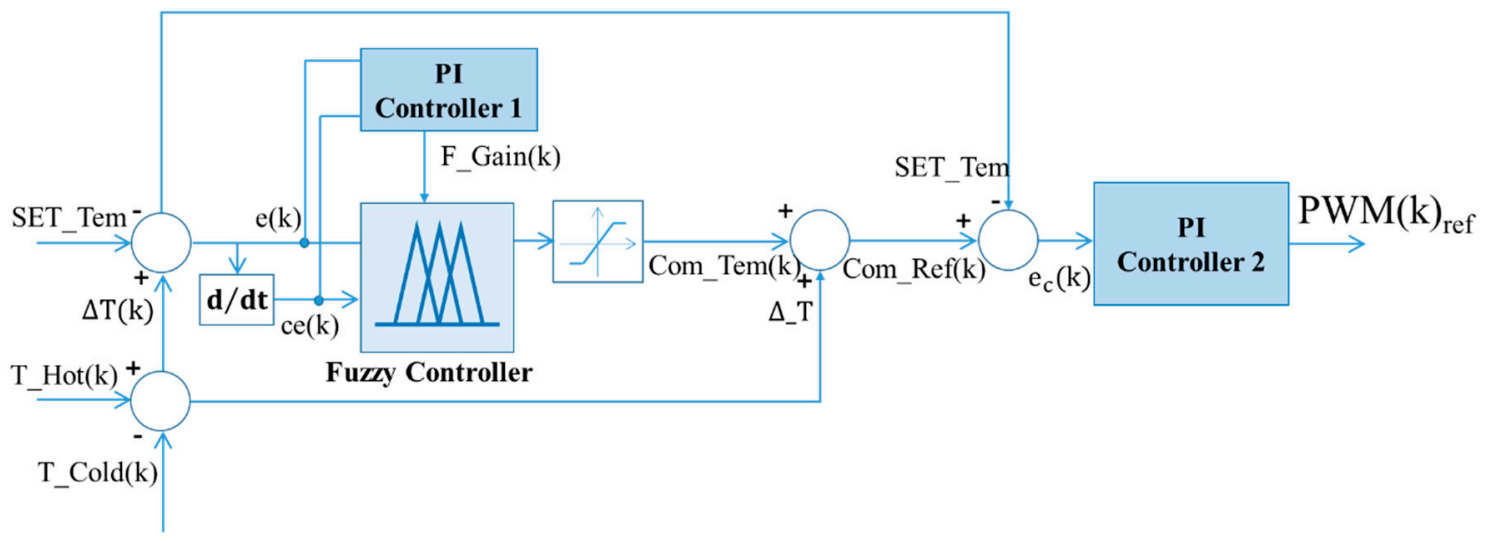

Figure 9. Structure of variable gain fuzzy proportional integration (VFPI) controller.

PI controller 1 outputs the output gain (F_Gain) of the fuzzy controller with the error (e) and the error change value (ce) as inputs.

$$
\mathrm{F}_{\mathrm{Gain}(\mathrm{k})}=\mathrm{k}_{\mathrm{p}} \times \mathrm{ce}(\mathrm{k})+\mathrm{k}_{\mathrm{i}} \times \mathrm{e}(\mathrm{k}) \times \mathrm{t}_{\mathrm{s}}
$$

Generally, the output value of the controller uses a certain range of values for the stability of the control, and sets a limit value for this. If the limit value is too large, the control range may be exceeded. If the limit value is too small, the control response is slowed down. Therefore, this paper proposes a method which improves the response performance by adjusting the limit value according to the operating state of the system. The control state can be divided into a transient state and a steady state. The transient state requires a lot of changes to track the set value. The steady state decreases the control value to maintain the current state. Therefore, this paper proposes a method to adjust the limit value according to the ratio of the set value (SET_Tem) of the error value (e (k)) using equation 19. In the transient state, the limit value increases because the error value e $(\mathrm{k})$ is large, and in the steady state, the error value e (k) decreases and the limit value decreases. As a result, a quick change is expected 
due to the control being performed at a larger value in the transient state, and the constant value is maintained by restricting the change of the control value in the steady state. Figure 10 shows the VFPI-VL (variable gain fuzzy proportional integration with variable limit) controller which controls the limit value of the output value of the fuzzy controller.

$$
\operatorname{Max} \_\lim (\mathrm{k})=\mathrm{k} \cdot \frac{\mathrm{e}(\mathrm{k})}{\mathrm{SET} \_\mathrm{Tem}}
$$

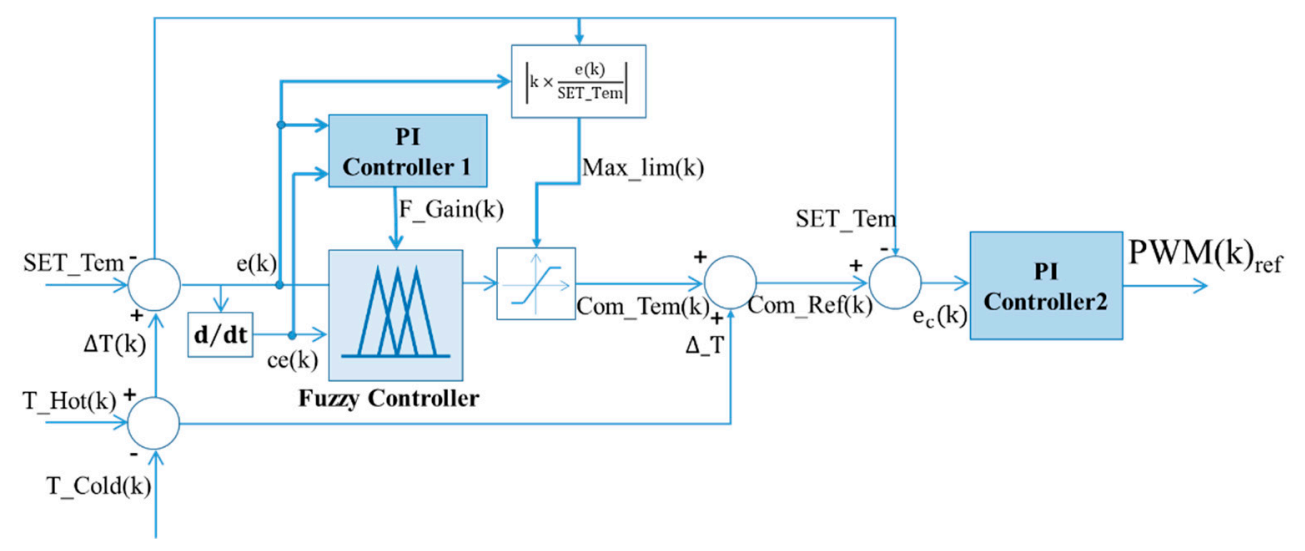

Figure 10. Structure of variable gain fuzzy proportional integration with variable limit (VFPI-VL) controller.

Figure 11 shows the flowchart for the PWM control that is the speed control signal of the fan. Set the reference temperature (Set_Tem) and calculate the temperature difference $(\Delta \mathrm{T})$ by measuring the temperature of the hot side (T_Hot) and cold side (T_Cold) of the thermoelectric element. This temperature difference is used to maintain the PWM through the main controller or to calculate a new PWM signal. The control ends when the set time is over or when the user enters the stop.

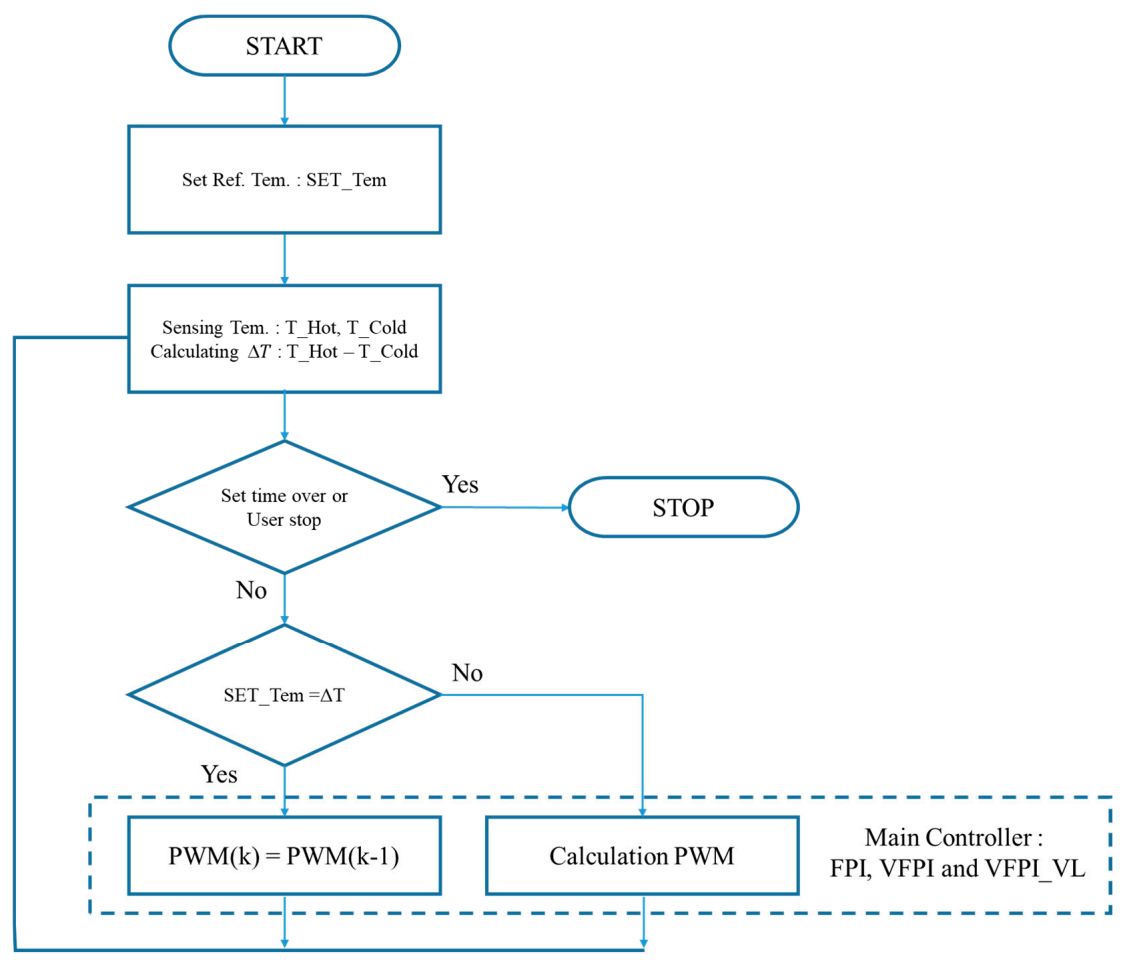

Figure 11. Flowchart for control. 


\section{Experiment Result}

Figure 12 shows the configuration of the experimental device to test the performance of the proposed method and Table 2 shows the characteristics of the main components used in the system configuration.

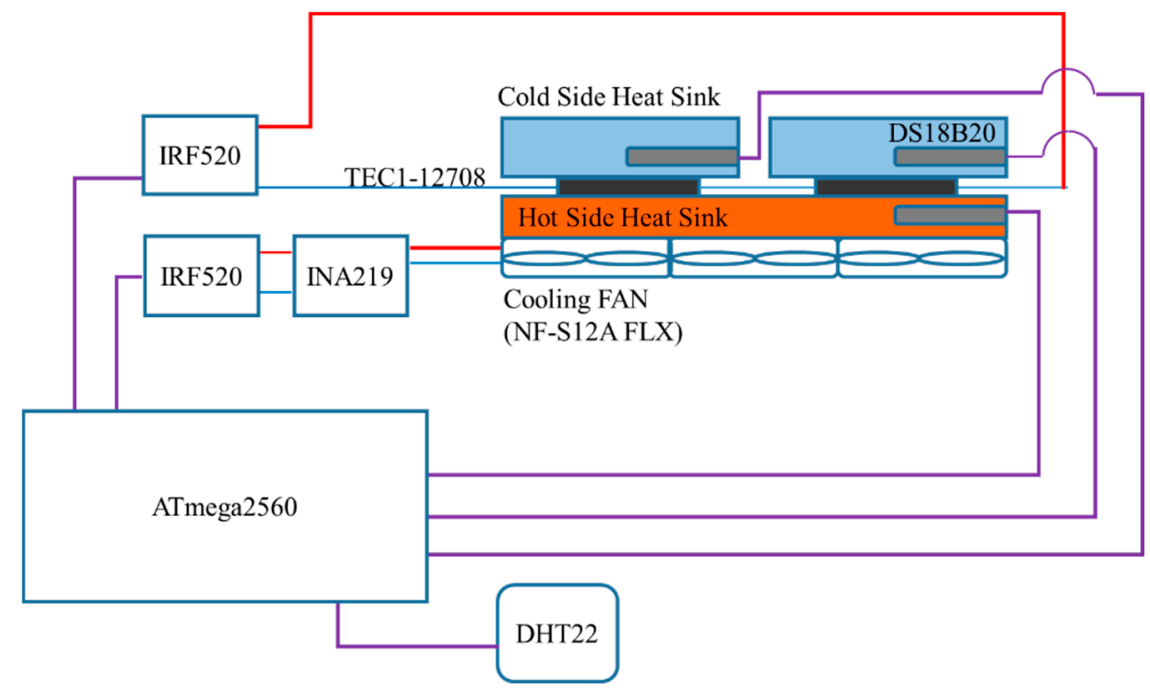

Figure 12. The system configuration diagram.

Table 2. The characteristics of the main components.

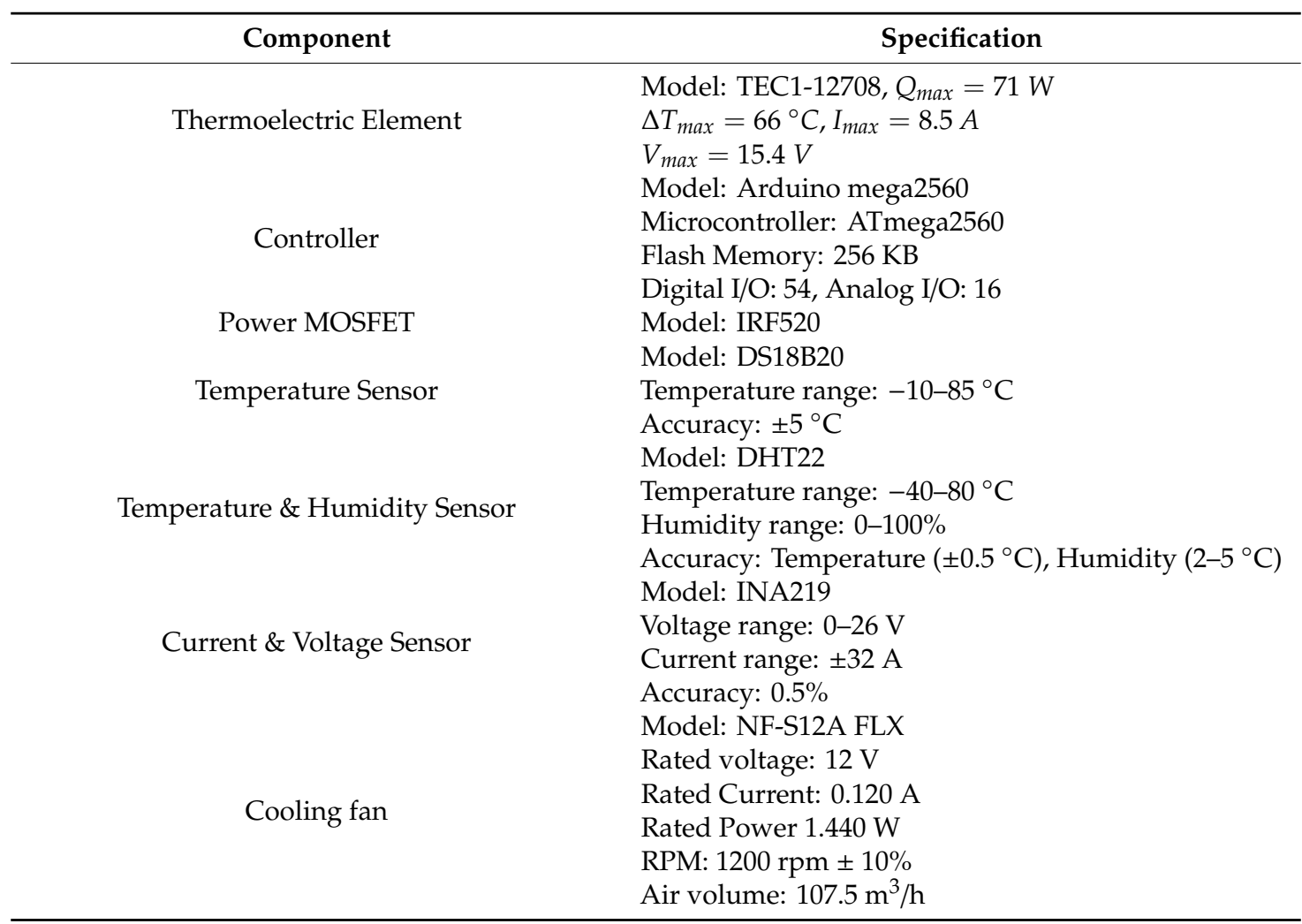

Arduino mega2580 (ARDUINO, Ivrea, Italy) is used as the main controller and a DS18B20 (DALLAS SEMICONDUCTOR, Dallas, TX, USA) temperature sensor is used for temperature of hot side and cold side of thermoelectric device. DHT22 (Aosong Electronics, Guangzhou, China) temperature/humidity sensor was used for ambient air temperature and IRF520 (VISHAY, Malvern, 
PA, USA) Power MOSFET for PWM control of thermoelectric device and fan. TEC1-12708 (HEBEI YUXIANG ELECTRONICS, HEBEI, China) is used as the thermoelectric element and NF-S12 FXL (Noctua, Wien, Austria) is used as the cooling fan. Details of the parts used are shown in Table 2. The sampling period for the experiment is $1 \mathrm{~s}$, and the switching frequency for PWM control is $980 \mathrm{~Hz}$.

The process for performance testing was as follows.

1. Keep ambient temperature and humidity constant for experiment.

2. Operate the experimental device until the temperature of the hold side and cold side of the thermoelectric device is stabilized.

3. When the temperature of the thermoelectric element stabilizes, data is acquired at the set time intervals.

4. Repeat steps 1 to 3 for all control methods.

Figure 13 shows the temperature change according to the cooling performance on the hot side of the thermoelectric element. Figure 13a shows the results when the hot side is not cooled, and Figure 13b shows the results when cooling. Table 3 shows the results of Figure 13 . When the hot side was cooled, the temperature of the hot side remained uniformly up to $28.81{ }^{\circ} \mathrm{C}$, so that the cold side temperature could be cooled up to $1.56{ }^{\circ} \mathrm{C}$. Therefore, cooling of the hot side is very important for cooling performance using a thermoelectric device.

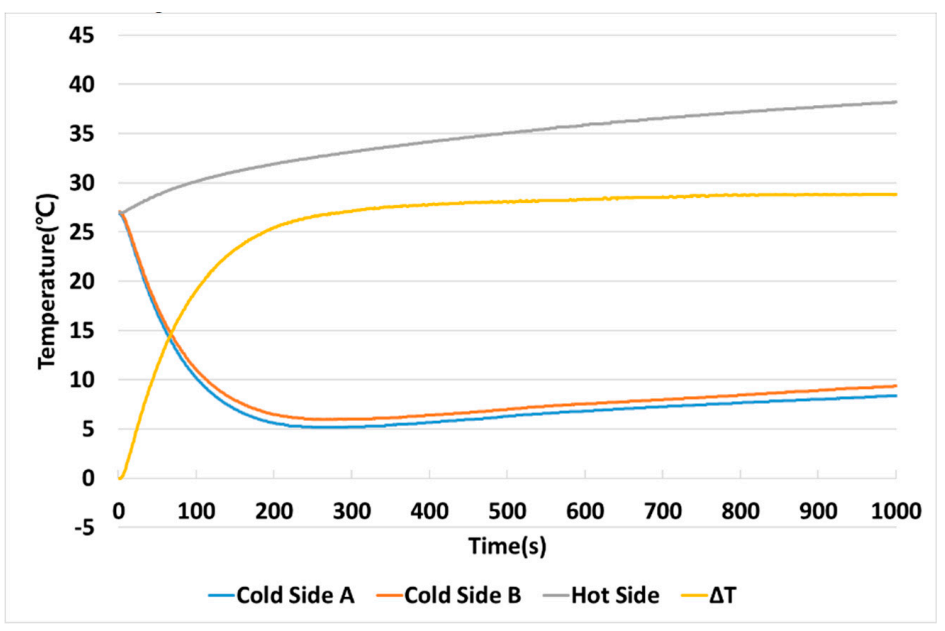

(a)

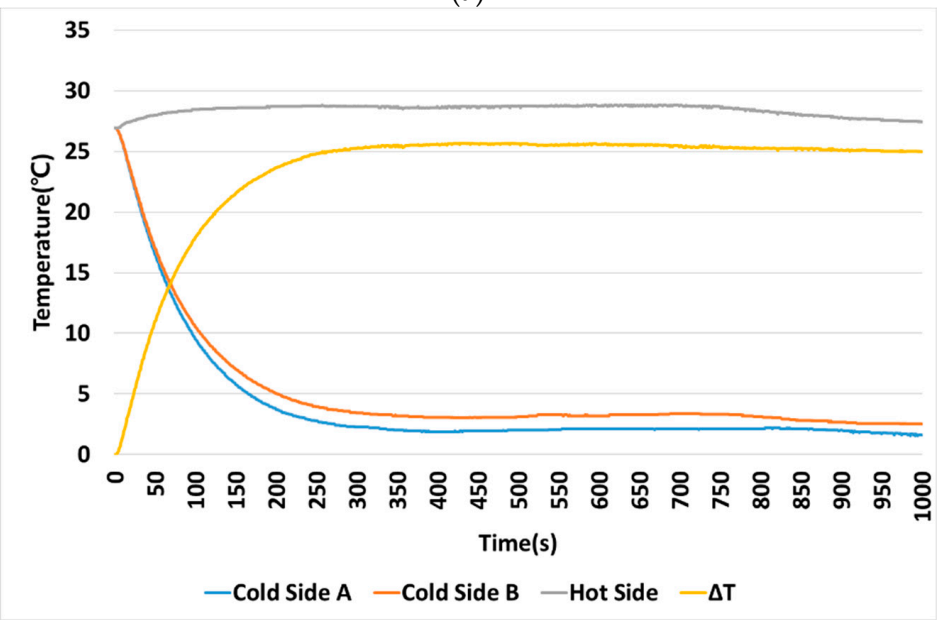

(b)

Figure 13. The temperature change according to the cooling on the hot side: (a) not cooled; (b) cooling. 
Table 3. Results of Figure 12.

\begin{tabular}{cccc}
\hline & $\begin{array}{c}\text { Lowest Temperature } \\
{\left[{ }^{\circ} \mathrm{C}\right]}\end{array}$ & $\begin{array}{c}\text { Highest Temperature } \\
{\left[{ }^{\circ} \mathrm{C}\right]}\end{array}$ & $\begin{array}{c}\text { Maximum Temperature } \\
\text { Difference }\left[{ }^{\circ} \mathrm{C}\right]\end{array}$ \\
\hline Non Cooling & 5.13 & 38.19 & 28.87 \\
Cooling & 1.56 & 28.81 & 25.69 \\
\hline
\end{tabular}

Figure 14 shows the ambient temperature conditions for the performance test of the PI control. The cooling performance using the fan is affected by the ambient temperature. Therefore, it is very important to match the ambient temperature conditions for performance comparison. In this paper, the cooling performance of the four methods is compared; the ambient temperature conditions for each performance comparison are as shown in Table 4 and the experiment was conducted at very similar temperature conditions.

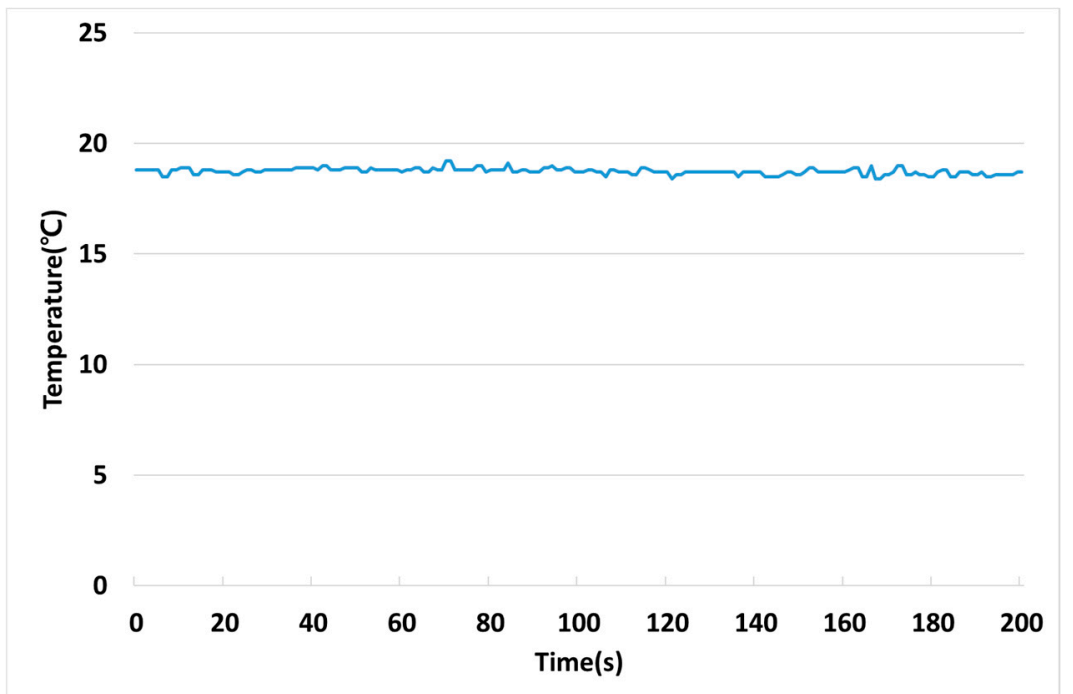

(a)

25

20

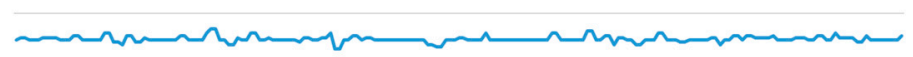

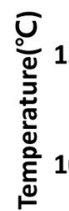

5

0

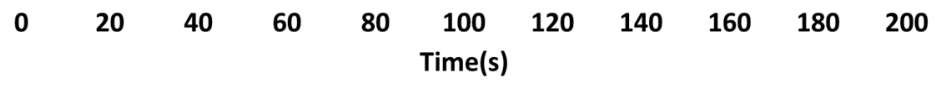

(b)

Figure 14. Cont. 


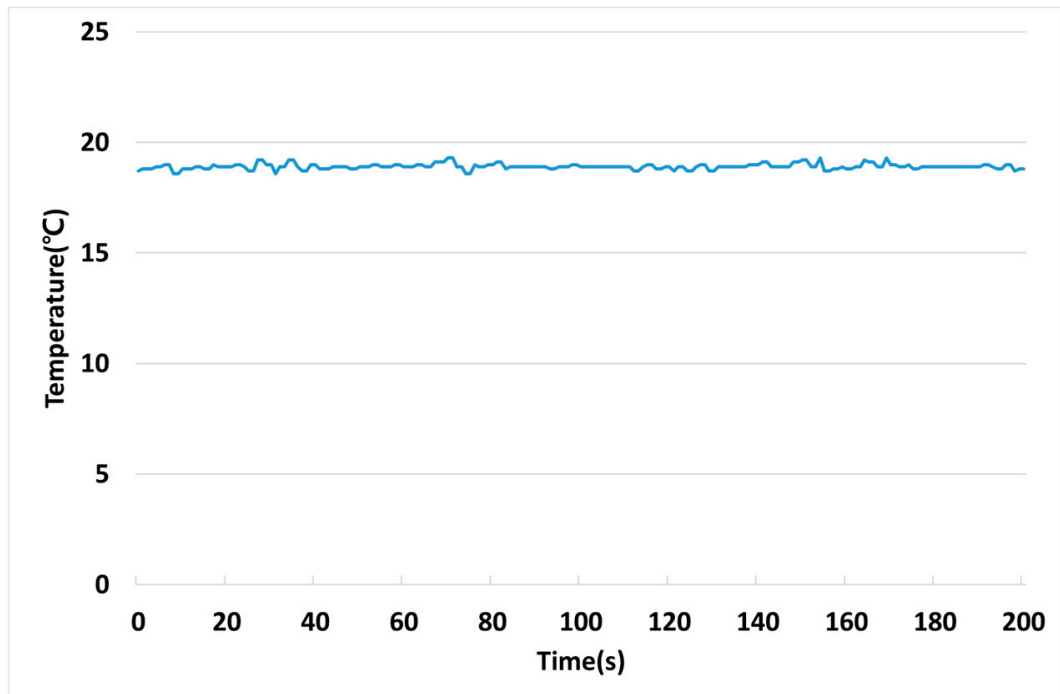

(c)

25

20

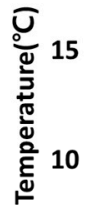

5

0

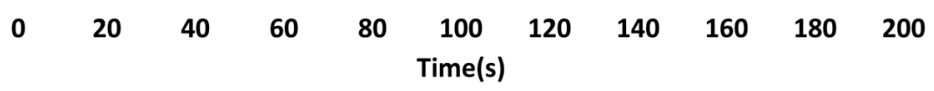

(d)

Figure 14. Ambient temperature conditions for performance testing: (a) PI, (b) FPI, (c) VFPI with fixed limit, and (d) VFPI with variable limit.

Table 4. Average value of ambient temperature condition for performance test.

\begin{tabular}{ccccc}
\hline & PI & FPI & $\begin{array}{c}\text { VFPI_with } \\
\text { Constant Limit }\end{array}$ & $\begin{array}{c}\text { VFPI with } \\
\text { Variable Limit }\end{array}$ \\
\hline Temperature $\left({ }^{\circ} \mathrm{C}\right)$ & 18.73 & 18.84 & 18.9 & 18.8 \\
\hline
\end{tabular}

Figure 15 is the experimental result of the PI controller, which is used most in the industrial field. The ability to maintain a constant temperature difference between the cold side and the hot side for thermoelectric cooling was tested. The setting temperature difference (SET_Tem) between the cold side and the hot side was set to $6^{\circ} \mathrm{C}$, and the temperature difference $(\Delta \mathrm{T})$ was controlled accordingly. Figure 15a shows the temperature change and Figure 15b shows the PWM signal for controlling the fan according to temperature. In case of Arduino, PWM is used from 0 to 255, PWM 0 means duty ratio 0\%, and PWM 255 means duty ratio 100\% [54]. 


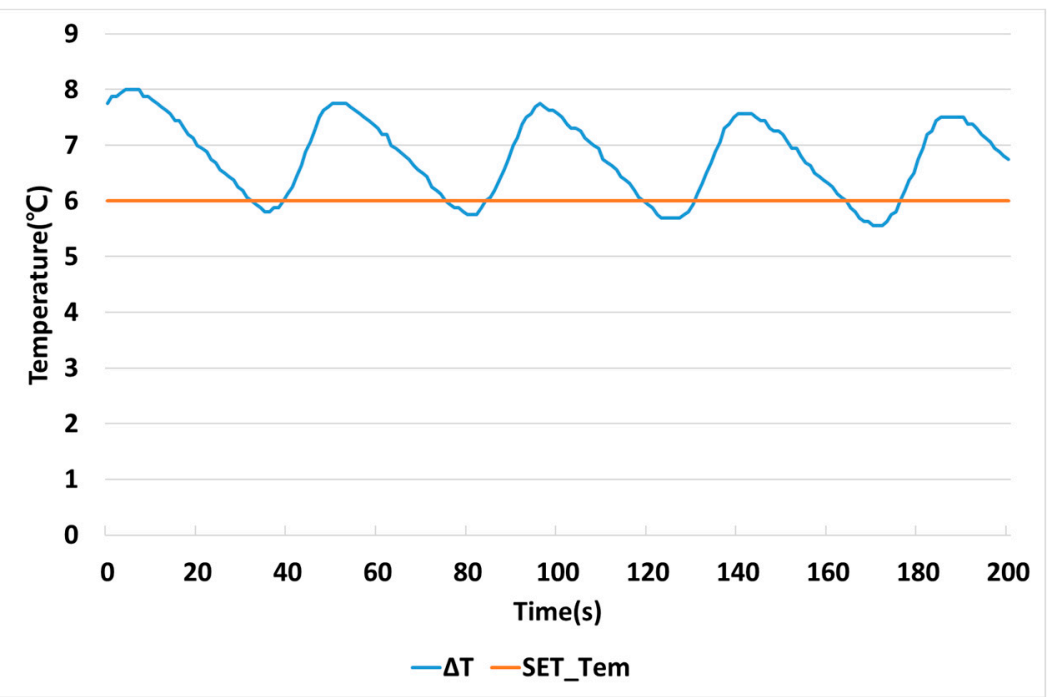

(a)

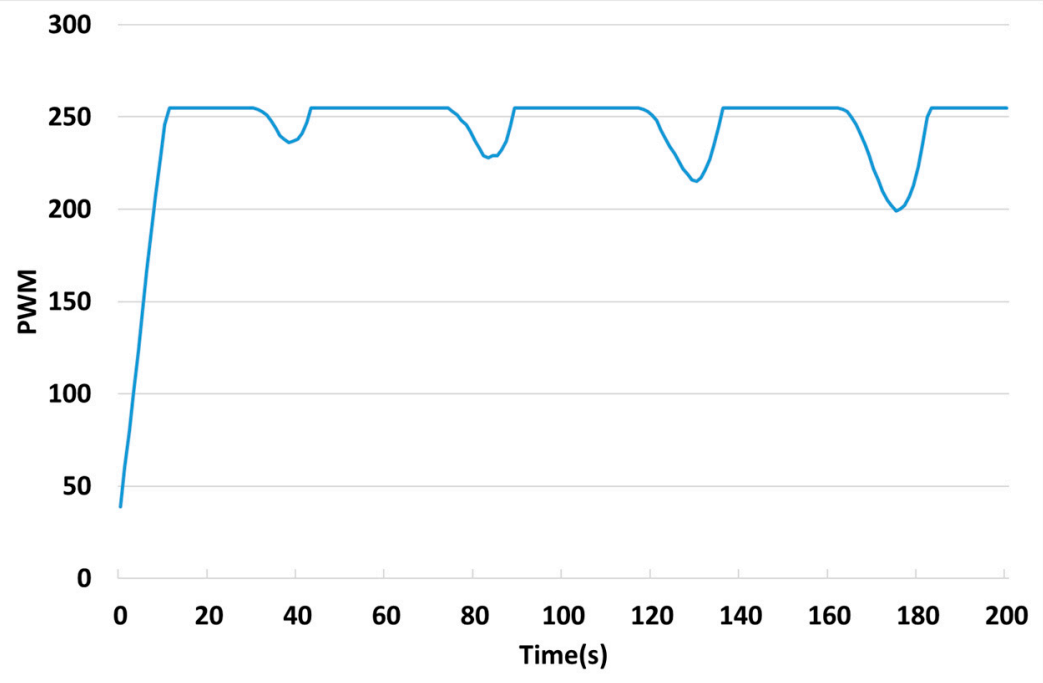

(b)

Figure 15. Temperature control by PI controller: (a) temperature and (b) Pulse width modulation (PWM) signal.

Table 5 shows the average temperature and the peak-to-peak temperature.

Table 5. Characteristics of temperature (PI controller).

\begin{tabular}{ccc}
\hline & Average Temperature & Peak-to-Peak Temperature \\
\hline Value $\left[{ }^{\circ} \mathrm{C}\right]$ & 6.79 & $5.56-8(2.44)$ \\
\hline
\end{tabular}

Figure 16 shows the power voltage, current, and power consumption of the PI controller. When the temperature is lower than the set temperature, the speed of the fan is lowered and the consumption current and power are reduced. Table 6 shows the average current, voltage, and consumption power. 

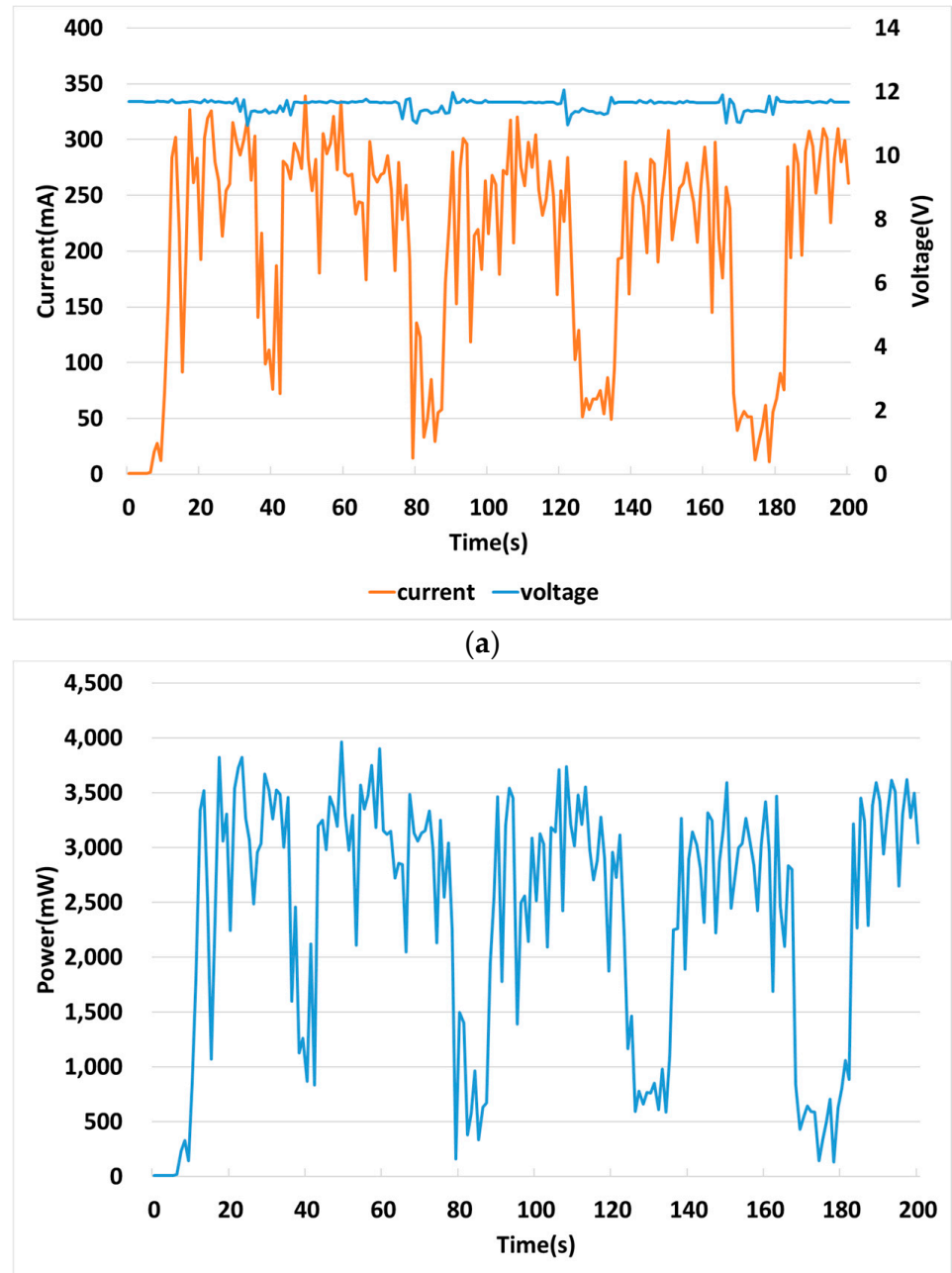

(b)

Figure 16. Input voltage, current, and power consumption (PI controller): (a) current and voltage and (b) power.

Table 6. Average current, voltage, and consumption power (PI controller).

\begin{tabular}{cccc}
\hline & Voltage $(\mathrm{V})$ & Current $\mathbf{m A})$ & Consumption Power $(\mathbf{m W})$ \\
\hline Value & 11.6 & 203.74 & 2369.6 \\
\hline
\end{tabular}

Figure 17 shows the temperature control results of the FPI controller using fuzzy control and the PI controller. In this paper, to improve the performance of the PI controller, the input value of the PI controller is adjusted by using the fuzzy controller. The set temperature difference between the cold side and the hot side of the thermoelectric element is set at $6^{\circ} \mathrm{C}$, and the temperature difference $(\Delta \mathrm{T})$ is controlled accordingly. In Figure 17a,Com_Tem represents the temperature compensated by the fuzzy controller. This value adjusts the input value of the PI controller to Com_ref. In Figure 17a, Zone A shows the temperature difference $(\Delta \mathrm{T})$ higher than the set temperature difference (SET_Tem). In this region, the speed of the fan needs to be increased because rapid cooling is required. In order for that to operate, the PI controller input value is amplified as the compensation temperature (com_Tem) increases. Zone $\mathrm{B}$ is a region in which the present temperature difference $(\Delta \mathrm{T})$ is lower than the set temperature difference (SET_Tem). In this interval, operation of the fan is not required and the compensation temperature (Com_Tem) is reduced. The PI controller amplifies the error value and thus enables more active temperature control. Figure $17 \mathrm{~b}$ shows the PWM signal by the FPI controller. 
Figure 18 shows the input voltage, current, and power of the FPI controller. Tables 7 and 8 show temperature characteristics, input voltage current, and power characteristics, respectively.

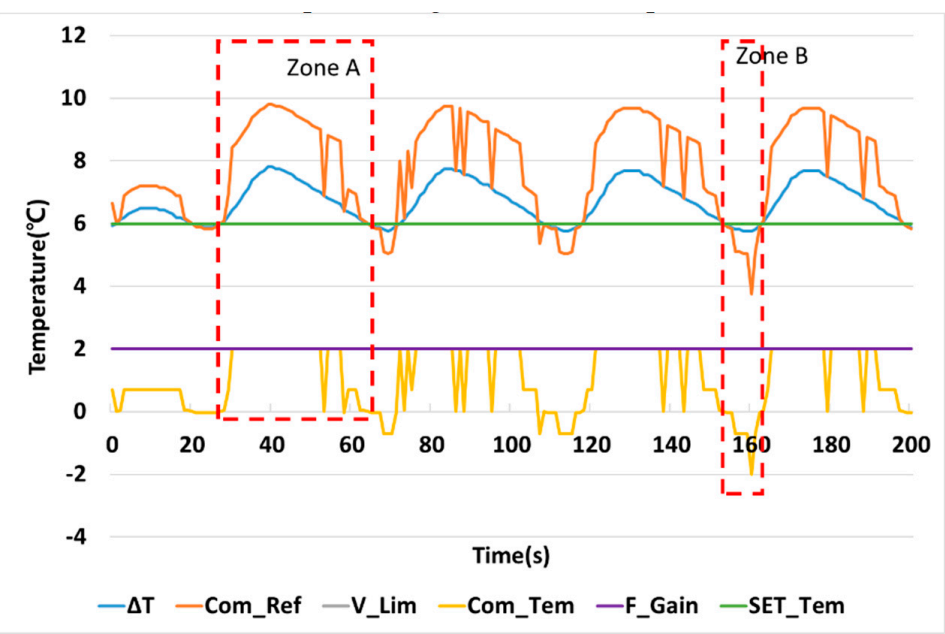

(a)

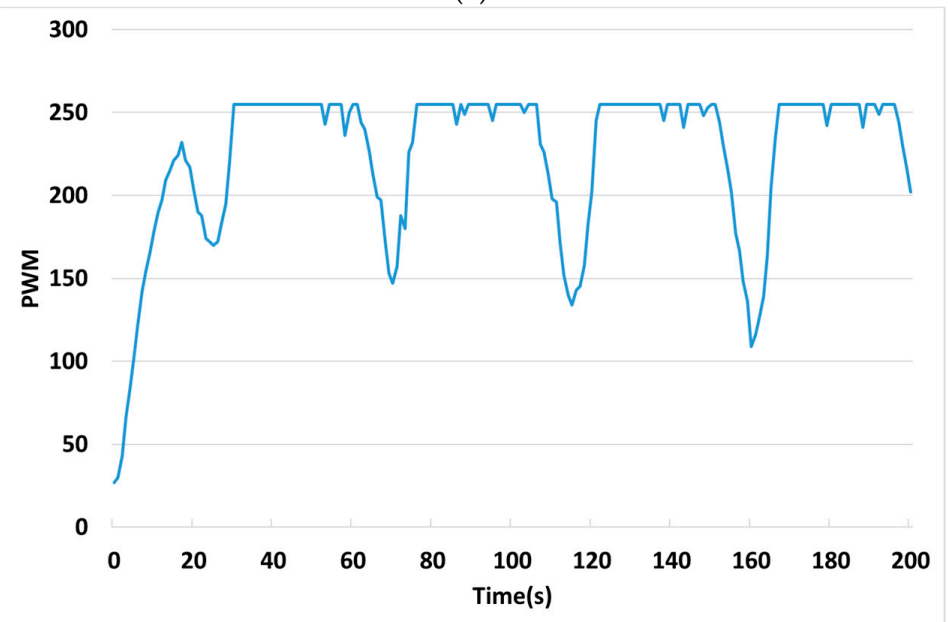

(b)

Figure 17. Temperature control by FPI controller: (a) temperature and (b) PWM signal.

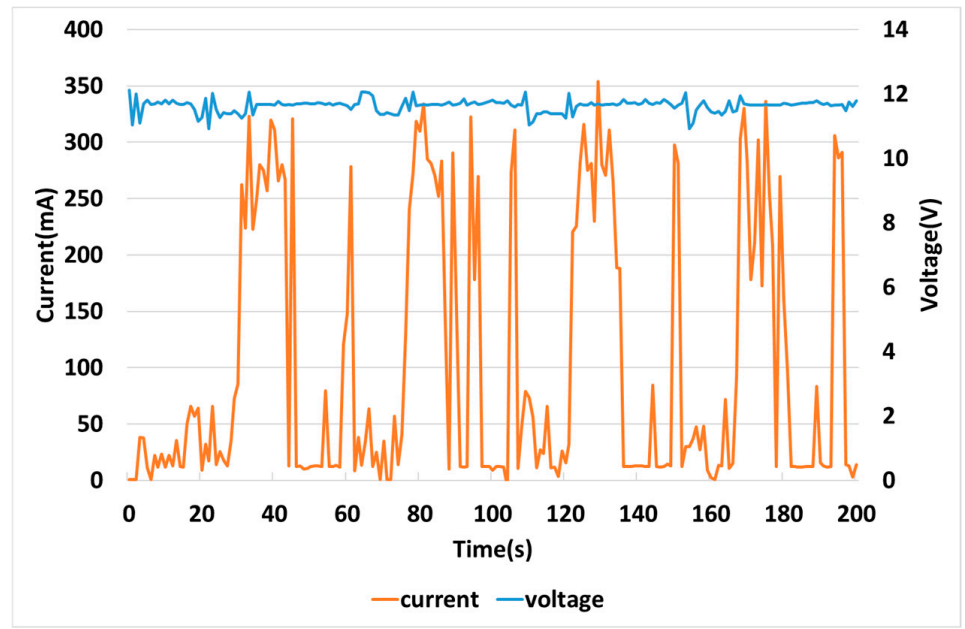

(a)

Figure 18. Cont. 


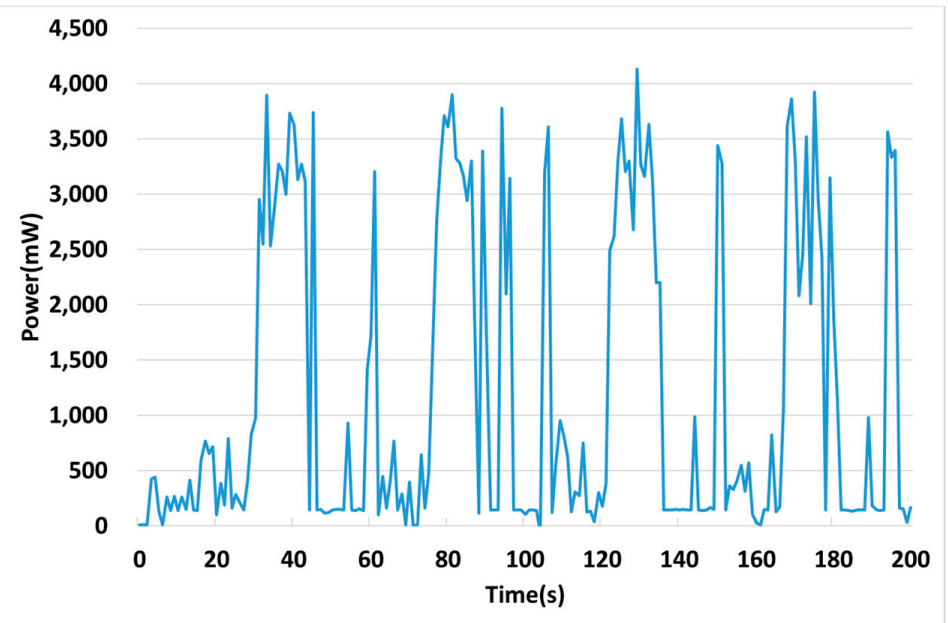

(b)

Figure 18. Input voltage, current, and power consumption (FPI controller): (a) current and voltage and (b) power.

Table 7. Characteristics of temperature (FPI controller).

\begin{tabular}{ccc}
\hline & Average Temperature & Peak-to-Peak Temperature \\
\hline Value $\left[{ }^{\circ} \mathrm{C}\right]$ & 6.71 & $5.75-7.81(2.06)$ \\
\hline
\end{tabular}

Table 8. Average current, voltage, and consumption power (FPI controller).

\begin{tabular}{cccc}
\hline & Voltage $(\mathrm{V})$ & Current $(\mathrm{mA})$ & Consumption Power $(\mathrm{mW})$ \\
\hline Value & 11.63 & 102.68 & 1196.68 \\
\hline
\end{tabular}

Figure 19 shows the temperature control result of VFPI that adjusts the gain of the fuzzy controller to improve the performance of the FPI. The FPI controller has a fixed gain of the fuzzy controller, but the VFPI controller changes the gain of the fuzzy controller to the PI controller according to the operating state. In Figure 19a, F_Gain represents the gain value of the fuzzy controller controlled by the PI controller and is adjusted according to the error between the set temperature difference (SET_tem) and the present temperature difference $(\Delta \mathrm{T})$. Adjusting the gain of the fuzzy controller can change the fan speed more quickly. Figure 19b shows the PWM signal by the VFPI controller. Figure 20 shows the input voltage, current, and power consumption of the VFPI controller. Tables 9 and 10 show the respective results of Figures 19 and 20.

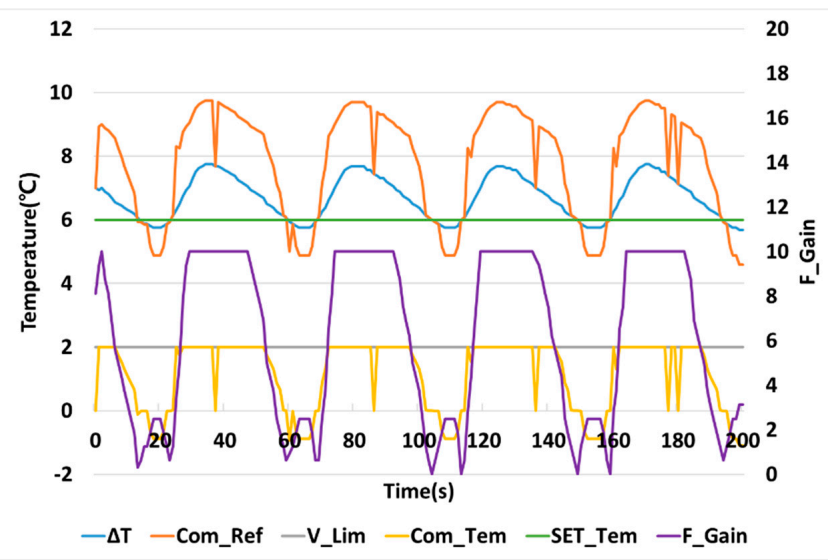

Figure 19. Cont. 
(a)

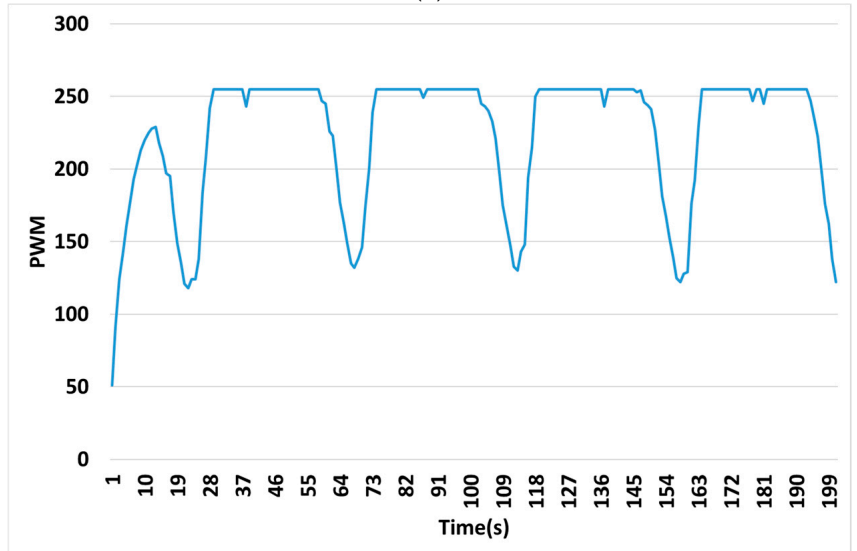

(b)

Figure 19. Temperature control by VFPI controller: (a) temperature and (b) PWM signal.

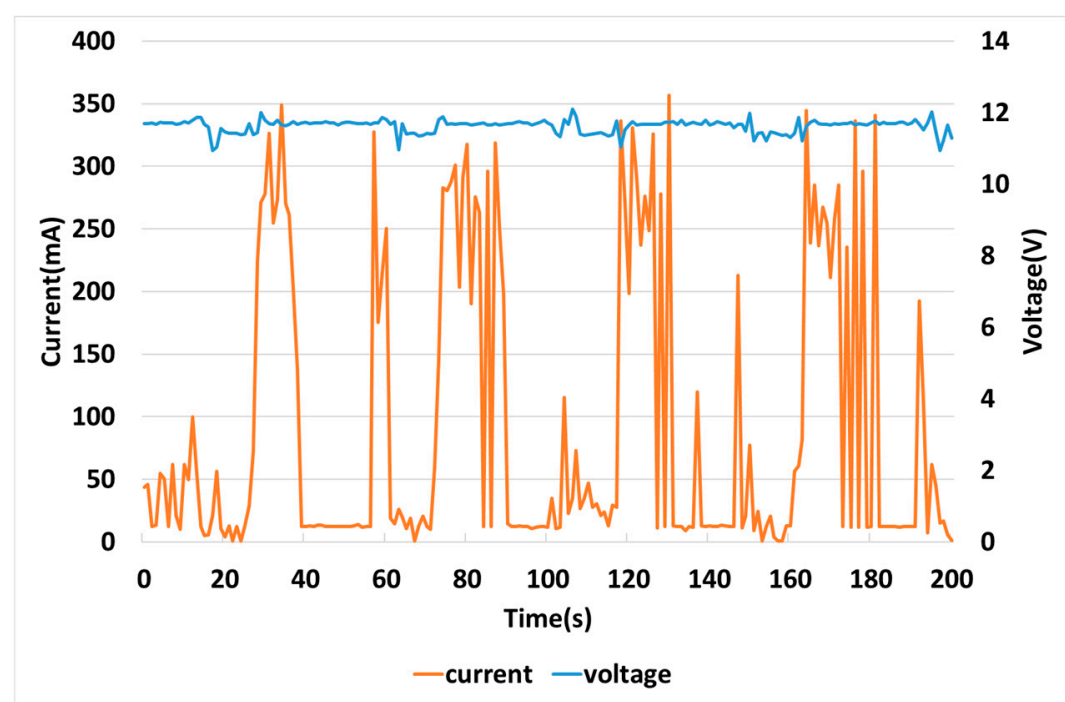

(a)

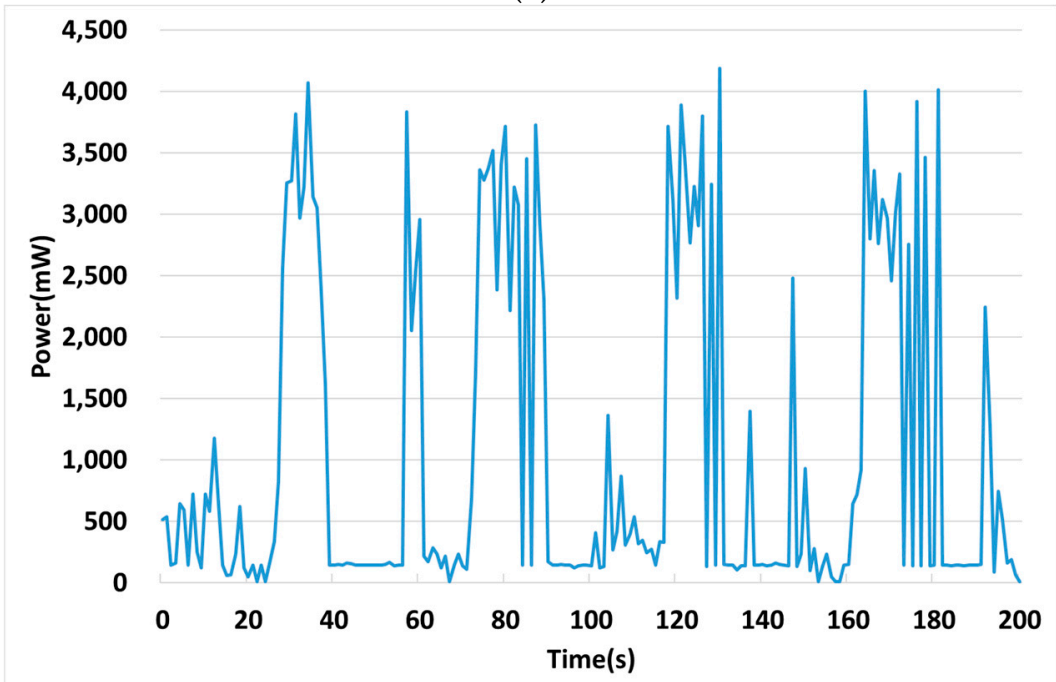

(b)

Figure 20. Input voltage, current, and power consumption (VFPI): (a) current and voltage and (b) power. 
Table 9. Characteristics of temperature (VFPI controller).

\begin{tabular}{ccc}
\hline & Average Temperature & Peak-to-Peak Temperature \\
\hline Value $\left[{ }^{\circ} \mathrm{C}\right]$ & 6.69 & $5.69-7.75(2.06)$ \\
\hline
\end{tabular}

Table 10. Average current, voltage, and consumption power (VFPI controller).

\begin{tabular}{cccc}
\hline & Voltage (V) & Current $(\mathbf{m A})$ & Consumption Power $(\mathbf{m W})$ \\
\hline Value & 11.63 & 90.01 & 1050.7 \\
\hline
\end{tabular}

Figure 21 shows the temperature control performance of variable fuzzy proportion integration-variable limit (VFPI-VL), which adjusts the limit value of the fuzzy controller to improve the performance of the VFPI controller. The VFPI-VL can be expected to produce fast speed changing because the limit value of the fuzzy controller is increasing. Fast speed changing improves the temperature control performance. Figure 21c shows the PWM signal by the VFPI-VL controller. Figure 22 shows input voltage, current and consumption power of the VFPI-VL controller.

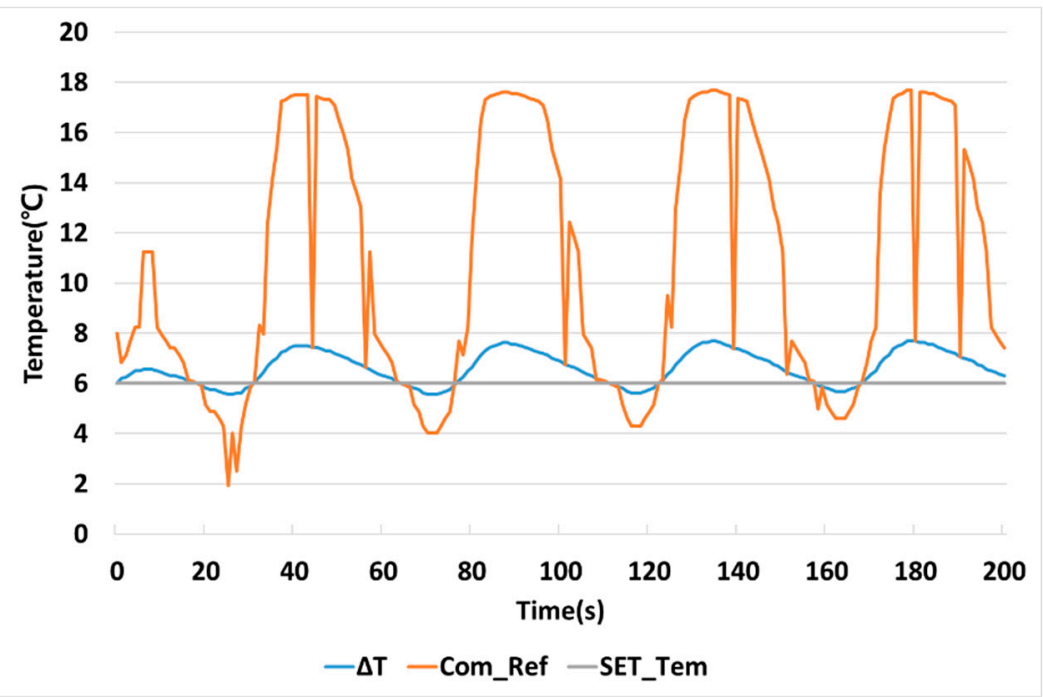

(a)

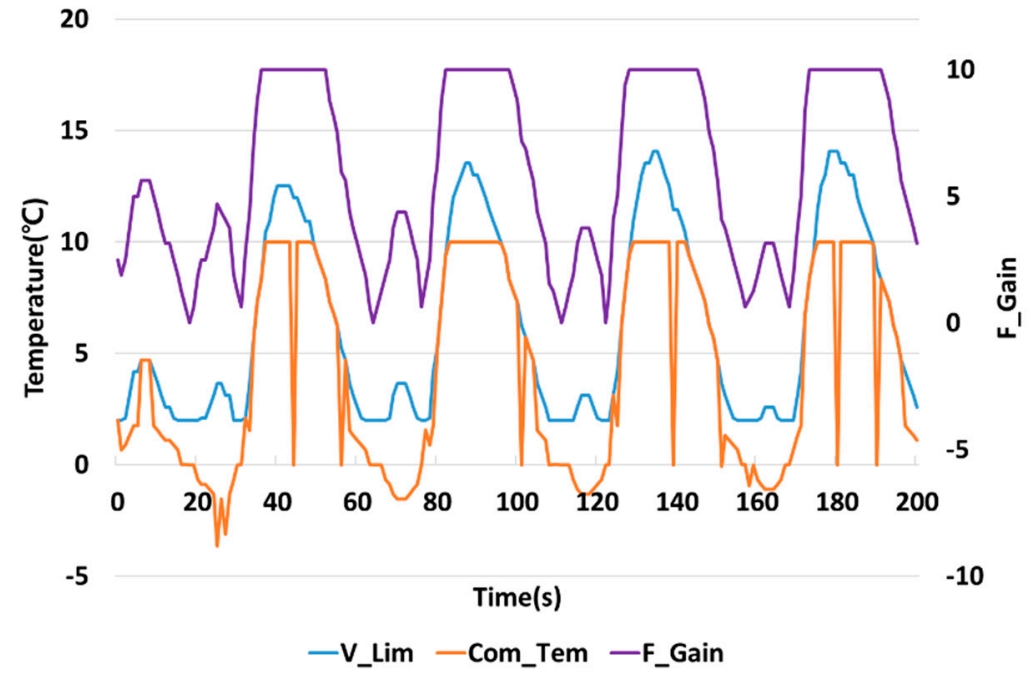

(b)

Figure 21. Cont. 


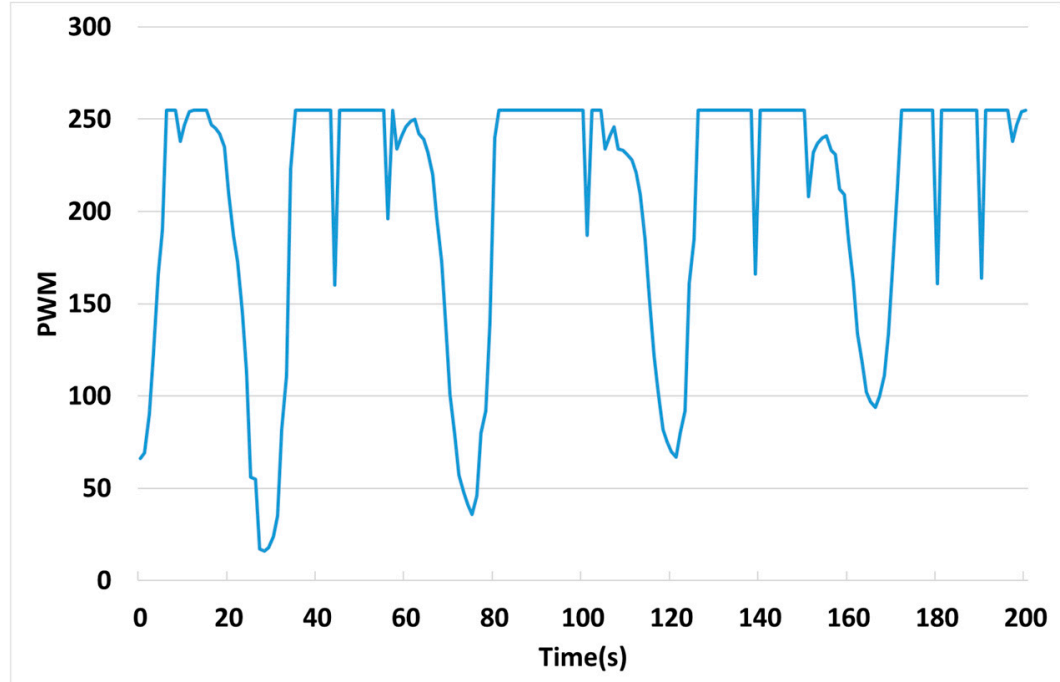

(c)

Figure 21. Temperature control by VFPI-VL controller: (a) setting temperature difference and current temperature difference, (b) gain and variable limit value of fuzzy controller, and (c) PWM signal.

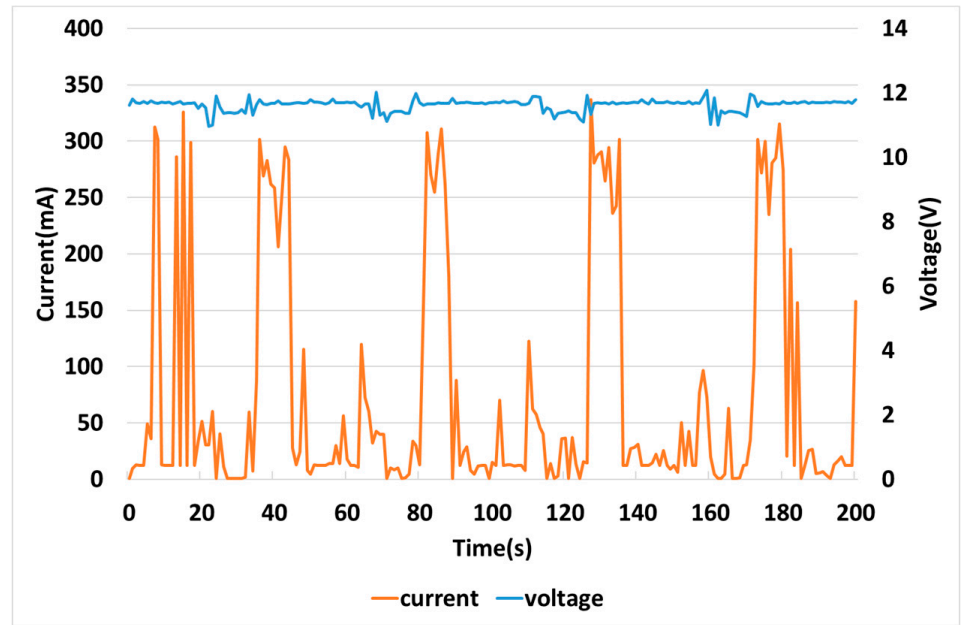

(a)

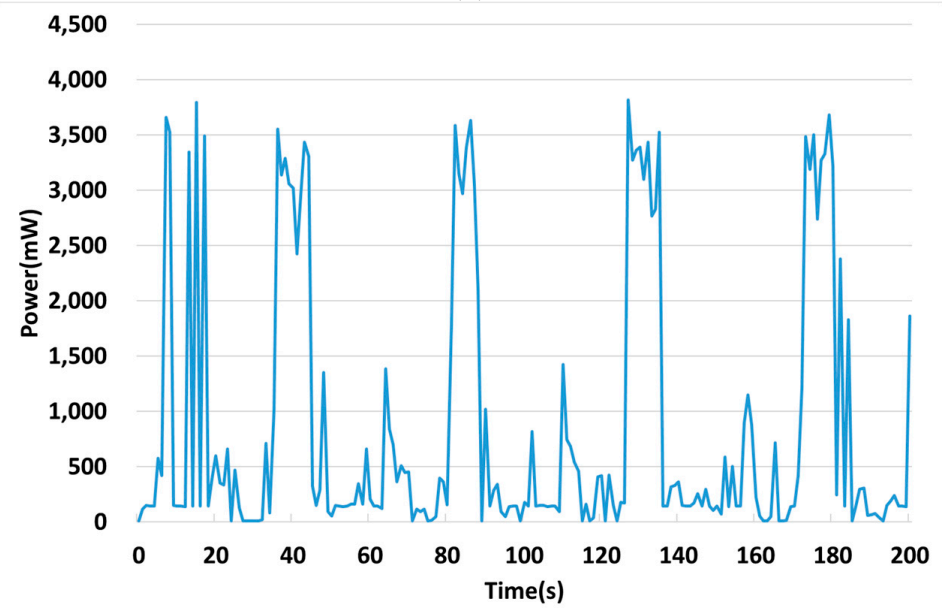

(b)

Figure 22. Input voltage, current, and power consumption (VFPI-VL): (a) current and voltage and (b) power. 
Table 11 shows the average temperature and peak-to-peak temperature of the controllers compared in this paper. The maximum temperature difference between the FPI and the VFPI was the smallest in the Table, but the VFPI-VL did not differ greatly. The VFPI-VL at the average temperature was the closest to the set temperature of $6^{\circ} \mathrm{C}$.

Table 11. Comparison of average temperature and peak-to-peak temperature.

\begin{tabular}{ccccc}
\hline & PI & FPI & VFPI & VFPI-VL \\
\hline $\begin{array}{c}\text { Average } \\
\text { Temperature }\left({ }^{\circ} \mathrm{C}\right)\end{array}$ & 6.79 & 6.71 & 6.69 & 6.61 \\
\hline Peak-to-peak & $5.56-8$ & $5.75-7.81$ & $5.69-7.75$ & $5.56-7.69$ \\
Temperature $\left({ }^{\circ} \mathrm{C}\right)$ & $(2.44)$ & $(2.06)$ & $(2.06)$ & $(2.13)$ \\
\hline
\end{tabular}

Table 12 shows the average of the voltage, current, and power consumption of the controllers used in this paper. All of the voltages were similar, and the VFPI-VL controller showed the lowest current and power. In particular, when the PI controller consumes $100 \%$ of the power consumed, the FPI is $50.5 \%$, the VFPI controller is $44.3 \%$, and the VFPI-VL is $32.6 \%$, and the power consumption is greatly reduced. Table 12 shows the average of the voltage, current and power consumption of the controllers used in this paper. All of the voltages were similar, and the VFPI-VL controller showed the lowest current and power. In particular, when the PI controller consumes $100 \%$ of the power consumed, the FPI is $50.5 \%$, the VFPI controller is $44.3 \%$, and the VFPI-VL is $32.6 \%$. The power consumption is greatly reduced. In addition, the average value of the PWM signal was the highest PI, and the VFPI-VL was the lowest.

Table 12. Comparison of average voltage, current, and consumption power.

\begin{tabular}{ccccc}
\hline & PI & FPI & VFPI & VFPI-VL \\
\hline Voltage (V) & 11.6 & 11.63 & 11.63 & 11.63 \\
\hline Current (A) & 0.20374 & 0.10268 & 0.09001 & 0.07388 \\
\hline Consumption & 2.3696 & 1.19668 & 1.0507 & 0.86177 \\
power (W) & $(100 \%)$ & $(50.5 \%)$ & $(44.3 \%)$ & $(32.6 \%)$ \\
\hline PWM average & 242.1 & 224.7 & 224.4 & 207.2 \\
\hline
\end{tabular}

In this paper, to improve the performance of the PI controller, which is most used in the industrial field, an FPI controller that controls the input value of the PI controller by a fuzzy controller is proposed. In addition, in order to improve the performance of the FPI controller, a VFPI controller that adjusts the gain of the fuzzy controller by the PI controller is proposed. Finally, a VFPI-VL method that changes the limit value of the fuzzy controller's output value according to operating conditions is introduced.

In this paper, the proportional and integral gains of the PI controllers used in the four controllers are the same. The input value of the PI controller, the gain of the fuzzy controller and the limit value of the fuzzy controller's output value are adjusted according to operating conditions. As a result, the fan cooling performance was improved. In particular, the VFPI-VL controller exhibited the best performance at constant temperature and power consumption.

\section{Conclusions}

This paper proposes a control method to improve energy efficiency and performance of the fan used in a cooling system. Industry 4.0 uses a lot of data. A large number of data centers are being built for this purpose. These data centers consist of IT equipment, power systems, cooling, and ventilation systems. Among them, cooling and ventilation systems have high rates of energy consumption. A cooling system using a fan is used as a general cooling system, and a cooling system using a thermoelectric element is used where cooling is required to a temperature lower than the 
ambient temperature or very precise temperature control is required. In order to maintain sufficient cooling performance in the cooling method using a thermoelectric element, the temperature of the hot side of the thermoelectric element must be continuously controlled. Therefore, this paper proposes various methods to improve the energy efficiency and performance of the fan which is mainly used in a cooling system. Generally, the PI controller is widely used for control. The PI controller is simple in structure and has a clear relationship between the gain and the control amount. However, the PI controller with a fixed gain value has limitations in performance improvement. The FPI controller adjusts the input value of the PI controller to the operating state using the fuzzy controller. The VFPI controller is a controller that adjusts the output gain value of the fuzzy controller used to adjust the gain of the PI controller. The VFPI-VL controller varies the limit value of the output value of the fuzzy controller according to the operation state.

In this paper, we propose a FPI method to control the input value of the PI controller, the VFPI controller to control the fuzzy controller output gain, and the VFPI-VL controller to adjust the output limit value of the fuzzy control. Each method enables faster control by amplifying the output according to the input value in the transient state. In particular, when the overshoot occurs, the control direction is reversed so that it can be stabilized more quickly. As a result, the rise time of the transient state was accelerated, and the stabilization time decreased in the steady state.

The controllers proposed in this paper actively control the temperature by adjusting the control variable value according to the operation state. This control performance improves the performance of the temperature maintaining ability, the average temperature, and the peak-to-peak temperature. The power consumption of the FPI controller, VFPI controller, and VFPI-VL controller was $50.5 \%, 44.3 \%$, and $32.6 \%$, respectively, of PI controller power consumption, thus improving the temperature control performance and energy efficiency. The methods presented in this paper can be applied to various variable speed systems as well as fans for cooling. The control methods presented through this paper have the disadvantage that the algorithm is complicated and the computational complexity is higher than that of the conventional PI controller. Therefore, research for improving processing speed through a microprocessor is needed.

Author Contributions: Conceptualization, J.-S.K. and J.-C.K.; Data Curation, J.-S.K.; Formal Analysis, J.-S.K.; Funding Acquisition, J.-H.H.; Investigation, J.-S.K. and J.-H.H.; Methodology, J.-H.H.; Project Administration, J.-H.H.; Resources, J.-S.K. and J.-C.K.; Software, J.-S.K., J.-H.H., and J.-C.K.; Supervision, J.-C.K.; Validation, J.-C.K.; Visualization, J.-H.H. and J.-C.K.; Writing-Original Draft, J.-S.K., J.-H.H., and J.-C.K.; Writing-Review \& Editing, J.-C.K.

Funding: This work was supported by the National Research Foundation of Korea (NRF) grant funded by the Korea government (MSIT) (No. 2017R1C1B5077157).

Conflicts of Interest: The authors declare no conflicts of interest. 


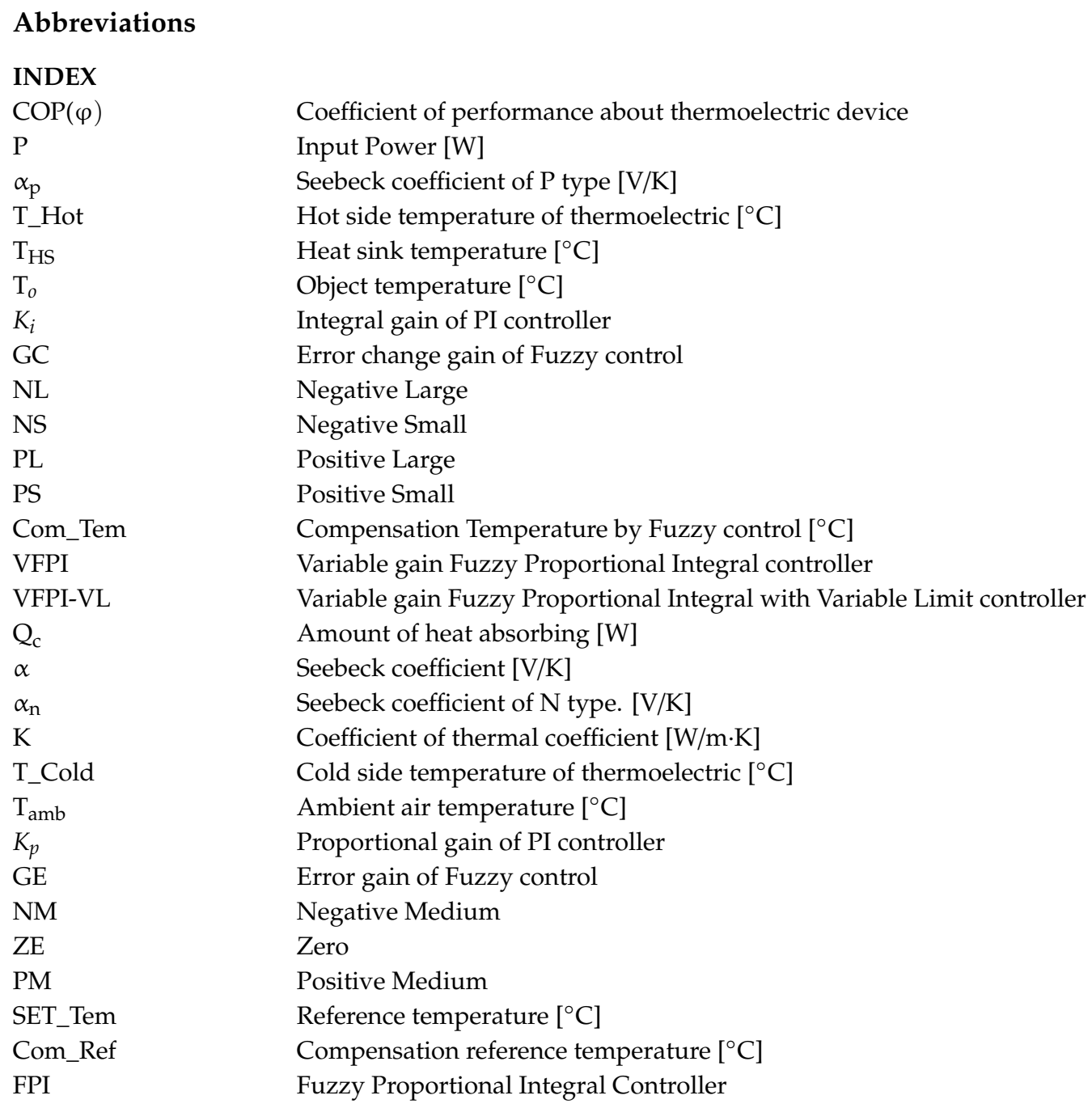

\section{References}

1. Schwab, K. The Fourth Industrial Revolution: What it means, how to respond. WORLD ECONOMIC FORUM Global Agenda. Available online: https://www.weforum.org/agenda/2016/01/the-fourth-industrialrevolution-what-it-means-and-how-to-respond/ (accessed on 14 January 2016).

2. Marcus, A. Data and the fourth industrial revolution. WORLD ECONOMIC FORUM Global Agenda. Available online: https://www.weforum.org/agenda/2015/12/data-and-the-fourth-industrial-revolution/ (accessed on 2 December 2015).

3. Data Center Cooling Methods. Available online: https://submer.com/blog/data-center-cooling-methods (accessed on 13 October 2015).

4. Zhang, X.; Lindberg, T.; Xiong, N.; Vyatkin, V.; Mousavi, A. Cooling Energy Consumption Investigation of Data Center IT Room with Vertical Placed Server. Energy Procedia 2017, 105, 2047-2052. [CrossRef]

5. DeepMind AI Reduces Google Data Centre Cooling Bill by 40\%. Available online: https://deepmind.com/ blog/deepmind-ai-reduces-google-data-centre-cooling-bill-40/ (accessed on 20 July 2016).

6. Shende, M.D. Cooling Of Electronic Equipments with Heat Sink: A Review of Literature. IOSR J. Mech. Civ. Eng. 2013, 5, 56-61. [CrossRef]

7. Kumar, A.; Behura, A.K. A Review of Electro Thermal Cooling Systems with Heat Sink. Int. J. Eng. Res. Manag. (IJERM) 2017, 4, 19-23.

8. Taylor, R.A.; Solbrekken, G.L. Comprehensive System-Level Optimization of Thermoelectric Devices for Electronic Cooling Applications. IEEE Trans. Compon. Packag. Technol. 2008, 31, 23-31. [CrossRef]

9. Patidar, S. Applications of Thermoelectric Energy: A Review. Int. J. Appl. Sci. Eng. Technol. 2018, 6, 1992-1996. [CrossRef] 
10. Ferro Tec, Ferro Tec, Thermoelectric Technical Reference-1.0 Introduction to Thermoelectric Cooling. Available online: https://thermal.ferrotec.com/technology/thermoelectric-reference-guide/thermalref01/ (accessed on 31 March 2019).

11. Astrain, D.; Vián, J.G.; Albizua, J. Computational model for refrigerators based on Peltier effect application. Appl. Therm. Eng. 2005, 25, 3149-3162. [CrossRef]

12. Alaoui, C. Peltier Thermoelectric Modules Modeling and Evaluation. Int. J. Eng. 2011, 5, 114-121.

13. Venugopal, A.; Narang, K.; Prakash, K.; Joshi, M. Cost-effective Refrigerator Using Thermoelectric Effect and Phase Change Materials. Int. J. of Sci. Eng. Res. 2014, 5, 624-627.

14. Dai, Y.; Wang, R.; Ni, L. Experimental investigation on a thermoelectric refrigerator driven by solar cells. Renew. Energy 2003, 28, 949-959. [CrossRef]

15. Chen, J.; Zhou, Y.; Wang, H.; Wang, J.T. Comparison of the optimal performance of single- and two-stage thermoelectric refrigeration systems. Appl. Energy 2002, 73, 285-298. [CrossRef]

16. Karimi, G.; Culham, J.; Kazerouni, V. Performance analysis of multi-stage thermoelectric coolers. Int. J. Refrig. 2011, 34, 2129-2135. [CrossRef]

17. Zhao, D.; Tan, G. A review of thermoelectric cooling: Materials, modeling and applications. Appl. Therm. Eng. 2014, 66, 15-24. [CrossRef]

18. Nikam, A.N.; Hole, J.A. A Review on use of Peltier Effects. Pratibha Int. J. Sci. Spiritual. Bus. Technol. (IJSSBT) 2014, 2, 6-12.

19. Zheng, X.F.; Liu, C.X.; Yan, Y.Y.; Wang, Q. A review of thermoelectric research-Recent developments and potentials for sustainable and renewable energy applications. Renew. Sustain. Energy Rev. 2014, 32, 486-503. [CrossRef]

20. Liu, D.; Zhao, F.Y.; Yang, H.X.; Tang, G.F. Thermoelectric mini cooler coupled with micro thermosiphon for CPU cooling system. Energy 2015, 83, 29-36. [CrossRef]

21. Zhou, Y.; Yu, J. Design optimization of thermoelectric cooling systems for applications in electronic devices. Int. J. Refrig. 2012, 35, 1139-1144. [CrossRef]

22. Espinosa, N.; Lazard, M.; Aixala, L.; Scherrer, H. Modeling a thermoelectric generator applied to diesel automotive heat recovery. J. Electron. Mater. 2010, 39, 1446-1455. [CrossRef]

23. Mori, M.; Yamagami, T.; Sorazawa, M.; Miyabe, T.; Takahashi, S.; Haraguchi, T. Simulation of fuel economy effectiveness of exhaust heat recovery system using thermoelectric generator in a series hybrid. SAE Int. J. Mater. Manuf. 2011, 4, 1268-1276. [CrossRef]

24. Hussain, Q.E.; Brigham, D.R.; Maranville, C.W. Thermoelectric exhaust heat recovery for hybrid vehicles. SAE Int. J. Engines 2009, 2, 1132-1142. [CrossRef]

25. Baatar, N.; Kim, S. A thermoelectric generator replacing radiator for internal combustion engine vehicles. Telkomnika 2011, 3, 523-530. [CrossRef]

26. Orr, B.; Akbarzadeh, A.; Mochizuki, M.; Singh, R. A review of car waste heat recovery systems utilizing thermo-electric generators and heat pipes. Appl. Therm. Eng. 2016, 101, 490-495. [CrossRef]

27. Lofy, J.; Bell, L.E. Thermo-electrics for environmental control in automobiles. In Proceedings of the Twenty-First International Conference on Thermoelectrics, Long Beach, CA, USA, 29 August 2002; pp. 471-476.

28. Jangonda, C.; Patil, K.; Kinikar, A.; Bhokare, R.; Gavali, M.D. Review of Various Application of Thermoelectric Module. Int. J. Innov. Res. Sci. Eng. Technol. 2016, 5, 3393-3400.

29. Ko, J.S.; Huh, J.H.; Kim, J.C. Improvement of Temperature Control Performance of Thermoelectric Dehumidifier Used Industry 4.0 by the SF-PI Controller. Processes 2019, 7, 98. [CrossRef]

30. Jiajitsawat, S. A Portable Hybrid Thermoelectric-Direct Evaporative Air Cooling System. Naresuan Univ. J. 2012, 20, 1-8.

31. Han, H.S.; Seo, y.; Ji, T.H.; Jee, Y.J.; Lee, D.W.; Jang, K.S.; Oh, D.H. Heat sink design for a thermoelectric cooling system. In Proceedings of the 2008 11th Intersociety Conference on Thermal and Thermomechanical Phenomena in Electronic Systems, Orlando, FL, USA, 28-31 May 2008; pp. 1222-1230.

32. Meerstetter engineering. TEC/Peltier Element Design Guide. Available online: https://www.meerstetter.ch/ compendium/tec-peltier-element-design-guide\#heatloads (accessed on 2 April 2019).

33. Meerstetter engineering. Peltier Element Efficiency. Available online: https://www.meerstetter.ch/ compendium/peltier-element-efficiency\#efficiencycop (accessed on 2 April 2019).

34. Farana, R.; Walek, B.; Janosek, M.; Zacek, J. Advantages of Fuzzy control Application in Fast and Sensitive Technological Processes. World Acad. Sci. Eng. Technol. Int. J. Electr. Comput. Eng. 2016, 9, 1270-1274. 
35. Khooban, M.H.; Soltanpour, M.R.; Abadi, D.N.M.; Esfahani, Z. Optimal Intelligent Control for HVAC System. J. Power Technol. 2012, 92, 192-200.

36. Khooban, M.H.; Adadi, D.N.M.; Alfi, A.; Siahi, M. Optimal Type-2 Fuzzy Controller For HVAC System. Automatika 2014, 55, 69-78. [CrossRef]

37. Khooban, M.H.; Niknam, T. A new intelligent online fuzzy tuning approach for multi-area load frefuency control: Self Adatpvie Modified Bat Algorithm. Int. J. Electr. Power Energy Syst. 2015, 71, 254-261. [CrossRef]

38. Khooban, M.H.; Naghash-Almasi, O.; Niknam, T.; Sha-Sadeghi, M. Intelligent robust PI adaptive control strategy for speed control of EV(s). IET Sci. Meas. Technol. 2016, 10, 433-441. [CrossRef]

39. Mamargo, J.R.; Oliveira, M.C.C. Principles of Direct Thermoelectric Conversion. Heat Anal. Thermodyn. Eff. 2011, 22, 93-106.

40. Landecker, K. Some Further Remarks on the Improvement of Peltier Junctions for Thermoelectric Cooling. Energy Convers. 1974, 14, 21-33. [CrossRef]

41. Ferro Tec. Thermoelectric Modules: Peltier Cooler Model 9501/127/040 B. Available online: https://thermal. ferrotec.com/products/peltier-thermoelectric-cooler-modules/9501_127_040-b/ (accessed on 2 April 2019).

42. Chang, S.-H.; Chen, P.-Y. Self-tuning gains of PI controllers for current control in a PMSM. In Proceedings of the 2010 5th IEEE Conference on Industrial Electronics and Applications, Taichung, Taiwan, 15-17 June 2010; pp. 1282-1286.

43. Ximei, Z.; Xianfeng, S. Neural-network-based self-tuning PI controller for Permanent Magnet Synchronous Motor. In Proceedings of the 2011 International Conference on Electrical Machines and Systems, Beijing, China, 20-23 August 2011; pp. 1-4.

44. Mokrani, L.; Abdessemed, R. A fuzzy self-tuning PI controller for speed control of induction motor drive. In Proceedings of the 2003 IEEE Conference on Control Applications, Istanbul, Turkey, 25 June 2003; pp. 785-790.

45. Basu, S. Realization of Fuzzy Logic Temperature Controller. Int. J. Emerg. Technol. Adv. Eng. 2012, 2, 151-155.

46. Rohin, M.; Adel, M.S. A Rule-Based Fuzzy Logic Controller for a PWM Inverter in a Stand Alone Wind Energy Conversion Scheme. IEEE Trans. Ind. Appl. 1996, 32, 57-65.

47. Shi, D.; Gao, G.; Gao, Z.; Xiao, P. Application of Expert Fuzzy PID method for Temperature Control of Heating Furnace. Procedia Eng. 2012, 29, 257-261.

48. Farah, N.S.Y.; Talib, M.H.N.; Ibrahim, Z.; Rasin, Z.; Rizman, Z.I. Experimental Investigation of Different Rules Size of Fuzzy Logic Controller for Vector Control of Induction Motor. J. Fundam. Appl. Sci. 2018, 10, 1696-1717.

49. Bajpai, D.; Mandal, A. Comparison of Different Rules Based Fuzzy Logic Controller for PMSM Drivers. IOSR J. Electr. Electron. Eng. (IOSR-JEEE) 2015, 10, 30-37.

50. Lazi, J.M.; Ibrahim, Z.; Sulaiman, M.; Patakor, F.A.; Isa, S.N.M. Fuzzy Logic Speed Controller with Reduced Rule Base for Dual PMSM Drivers. Int. J. Electr. Comput. Eng. 2011, 5, 623-628.

51. Ohaid, Z.A.; Salman, S.A.; Saadon, I. Analysis and Performance Evaluation of the Position Control of an AC Motor Using PD-PI-PID Fuzzy Logic Controller. J. Math. Comput. Sci. 2014, 4, 790-804.

52. Bennasar, A.; Abbou, A.; Akherraz, M.; Barara, M. Fuzzy Logic Speed Control for Sensorless Indirect Field Oriented of Induction Motor Using and Extended Kalman Filter. Int. Rev. Autom. Cotnrol 2013, 6, 332-339.

53. Khalid, M.; Omatu, S. Fuzzy Logic Control. J. Teknol. 1993, 21, 20-40. [CrossRef]

54. ARDUINO. PWM. Available online: https://www.arduino.cc/en/Tutorial/PWM (accessed on 17 May 2019). 